NBER WORKING PAPER SERIES

\title{
TEMPORAL INSTABILITY OF RISK PREFERENCE AMONG THE POOR: EVIDENCE FROM PAYDAY CYCLES
}

\author{
Mika Akesaka \\ Peter Eibich \\ Chie Hanaoka \\ Hitoshi Shigeoka \\ Working Paper 28784 \\ http://www.nber.org/papers/w28784 \\ NATIONAL BUREAU OF ECONOMIC RESEARCH \\ 1050 Massachusetts Avenue \\ Cambridge, MA 02138 \\ May 2021
}

The authors thank Keith Marzilli Ericson, David Freeman, Alex Imas, Stephan Meier, Takeshi Murooka, Krishna Pendakur, and seminar participants at Osaka University (ISER and OSIPP), Simon Fraser University, NBER Aging Spring meeting, and the Joint Workshop on Behavioral Economics for their comments and suggestions. The Health and Retirement Study (HRS) is sponsored by the National Institute on Aging and is conducted by the University of Michigan. The Japanese Study of Aging and Retirement (JSTAR) is conducted by the Research Institute of Economy, Trade, and Industry (RIETI), Hitotsubashi University, and University of Tokyo. The Japanese General Social Surveys (JGSS) are conducted by Osaka University of Commerce, in collaboration with the Institute of Social Science at the University of Tokyo. Akesaka acknowledges financial support from JSPS KAKENHI (15H05728, 20H05631, 20K13511, 21H04397) and the Joint Usage/Research Center for Behavioral Economics at ISER. Hanaoka acknowledges financial support from JSPS KAKENHI (17K03783, 19H05487, 20K20418). Any errors are our own. The views expressed herein are those of the authors and do not necessarily reflect the views of the National Bureau of Economic Research.

NBER working papers are circulated for discussion and comment purposes. They have not been peer-reviewed or been subject to the review by the NBER Board of Directors that accompanies official NBER publications.

(C) 2021 by Mika Akesaka, Peter Eibich, Chie Hanaoka, and Hitoshi Shigeoka. All rights reserved. Short sections of text, not to exceed two paragraphs, may be quoted without explicit permission provided that full credit, including $\odot$ notice, is given to the source. 
Temporal Instability of Risk Preference among the Poor: Evidence from Payday Cycles

Mika Akesaka, Peter Eibich, Chie Hanaoka, and Hitoshi Shigeoka

NBER Working Paper No. 28784

May 2021

JEL No. D81,D91,I32

\section{ABSTRACT}

The poor live paycheck to paycheck and are repeatedly exposed to strong cyclical income fluctuations. We investigate whether such income fluctuations affect risk preference among the poor. If risk preference temporarily changes around payday, optimal decisions made before payday may no longer be optimal afterward, which could reinforce poverty. By exploiting Social Security payday cycles in the US, we find that risk preference among the poor relying heavily on Social Security changes around payday. Rather than cognitive decline before payday, the deterioration of mental health and relative deprivation may play a role. We find similar evidence among the Japanese elderly.

Mika Akesaka

Institute of Social and Economic Research

Osaka University

6-1, Mihogaoka

Ibaraki, Osaka

Japan

akesaka@iser.osaka-u.ac.jp

Peter Eibich

Max Planck Institute for Demographic

Research

Konrad-Zuse-Str. 1

18057 Rostock

Germany

eibich@demogr.mpg.de
Chie Hanaoka

Faculty of Economics

Toyo University

Hakusan 5-28-20

Bunkyo-Ku, Tokyo

JAPAN

hanaoka077@toyo.jp

Hitoshi Shigeoka

Department of Economics

Simon Fraser University

8888 University Drive, WMC 4653

Barnaby, BC V5A 1S6

CANADA

and NBER

hitoshi_shigeoka@sfu.ca 


\section{Introduction}

The poor often live paycheck to paycheck, and heavily rely on government benefits such as pension and social welfare programs. Numerous studies have documented expenditure increasing sharply after the receipt of such payment, suggesting that these individuals lack financial resources before payday. ${ }^{1}$ Since these payments are usually periodic (e.g., monthly), the poor are repeatedly exposed to strong and nearly unavoidable cyclical income fluctuations.

This paper asks whether such frequent, temporary and anticipated income fluctuations induced by periodic payments change individuals' risk preference. Risk preference is a fundamental determinant of everyday economic decision-making (e.g., payday loans and purchase of lottery tickets) as well as issues with long-term consequences (e.g., saving, investment, and insurance choices) for individuals. As a result, in many circumstances, the temporal change in risk preference around payday — if it exists - indicates that the optimal risk decisions made before payday may no longer be optimal after payday at a different level of risk preference. If such non-optimal decisions further deepen the poor's dependence on periodically paid welfare programs, such time-varying risk preference induced by periodic payment may be another source of the feedback loop that reinforces poverty. As periodic payment of pensions, salaries, and social welfare programs is ubiquitous around the world, ${ }^{2}$ the answers to this universal question can have substantial policy relevance.

We test this question by exploiting Social Security payday cycles in the United States. In our sample period, Social Security benefits are paid on the $3^{\text {rd }}$ of every month. Past research has documented that expenditures and food consumption increase sharply on the $3^{\text {rd }}$ of the month (Stephens 2003; Mastrobuoni and Weinberg 2009), indicating that individuals face scarce financial resources before payday. Since the restricted version of the Health and Retirement Study (HRS) - the primary working data in this study — includes the exact dates on which interviews took place, we can compare the risk preference of those who were interviewed before and after the Social Security payday (i.e., $3^{\text {rd }}$ of the month). We run balanced tests to ensure the random assignment of interview dates to respondents over the month. This approach allows us to obtain the causal estimate of the effect of income fluctuation around payday on the risk

\footnotetext{
${ }^{1}$ See, for example, studies in the US (Wilde and Ranney 2000; Stephens 2003; Shapiro 2005; Mastrobuoni and Weinberg 2009; Hastings and Washington 2010) and the UK (Huffman and Barenstein 2005; Stephens 2006). ${ }^{2}$ E.g., Supplemental Nutrition Assistance Program (SNAP) and Supplemental Security Income (SSI) in the US.
} 
preference of Social Security beneficiaries. ${ }^{3}$

We find that risk preference - measured by the hypothetical gambles over lifetime income in the HRS — changes around payday among Social Security beneficiaries. ${ }^{4}$ In particular, individuals who rely heavily on Social Security income and are indeed poor (average annual household income is USD 24,688), become more risk-tolerant just before payday —when financial resources are scarce - than after payday. In terms of magnitude, the risk tolerance parameter is higher by $0.43 \mathrm{SD}$ before payday than after payday, which cannot be dismissed as noise. We do not find the same systematic pattern for those who are relatively rich and as a result do not rely heavily on Social Security benefits, suggesting that dependence on this income plays a role.

Our results are robust to different ways of defining heavy dependence on Social Security income, different ways of constructing outcomes, and different specifications. Specifically, our results do not need to rely on any particular form of utility function to derive risk preference parameters. We also carry a battery of placebo tests to support our results. Taken together, these results suggest that the risk preference of the elderly poor, who rely heavily on Social Security benefits, may not be temporally stable in short intervals, at least in our setting.

To probe the mechanisms of temporal change in risk preference around payday, we first examine cognitive functioning around payday. Mullainathan and Shafir, among other researchers, argue that financial strain impedes cognitive function and worsens the quality of decision-making. ${ }^{5}$ We do not find any before-after payday difference in cognition measures, implying that cognitive decline around payday does not explain the temporal shift in risk preference. Instead, we find suggestive evidence that mental state plays some role. We find that individuals are more likely to be depressed before than after payday. Since we do not observe any changes in mental health among individuals who do not heavily rely on Social Security

\footnotetext{
${ }^{3}$ Whereas our across-subjects design does not allow us to compare the level or rank stability of risk preference in the same individual (within subject), this approach still enables us to compare the aggregate of risk preference and obtain the causal estimates of temporal financial shocks on risk preference. Mastrobuoni and Weinberg (2009) take a similar across-subjects approach which exploits random interview dates around Social Security payday.

${ }^{4}$ This gamble is clearly framed as one of long-run risk, not small-to-moderate gambles that can be reimbursed immediately. This mitigates the concern that liquidity constraints restricting individuals' choices drive our results.

${ }^{5}$ See Shah et al. (2012), Mullainathan and Shafir (2013), and Mani et al. (2013). See also Schilbach et al. (2016) and Dean et al. (2019) for the growing literature on the psychology of the poor.
} 
benefits, the deterioration of mental health before payday might be one channel through which risk preference changes around payday.

To assess external relevance, we also examine the same question using data for the elderly in Japan. This exercise is more than a simple replication, since the US and Japan have very different baseline risk preferences. Falk et al.'s (2018) global survey shows that Japan is one of the most risk-averse countries whereas the US is the opposite. Furthermore, the public pension in Japan is paid on the 15 th of every even month instead of every month like in the US. This twomonth interval between paydays allows us to include week-of-the-month fixed effects (e.g., the effect of the first week of the month) for Japan, which is impossible in the case of the US. This setting mitigates the concern that the US results are driven by other events at the beginning of the calendar month, such as housing payment. ${ }^{6} \mathrm{We}$ find corroborative evidence consistent with the results found in the HRS data: Japanese individuals also become more risk-tolerant just before payday.

We also revisit the potential mechanisms using Japanese data. We find that Japanese respondents, who rely heavily on pension benefits, feel financially anxious before payday, which is in line with the finding on depression in the US. Interestingly, respondents also feel relatively deprived before payday, and hence, another potential mechanism could be that such feeling induces one to take more risks, as one strives to catch up to their comparison standards. Although we cannot precisely pin down the underlying mechanisms, mental state and the feeling of relative deprivation, and their interplays, may influence temporal fluctuations in risk preferences around payday.

This study is related to at least two strands of the literature. First, it adds new insight to the literature on poverty and individual preferences (e.g., Carvalho et al. 2016). ${ }^{7}$ The literature argues that the economic environment of the poor shapes their individual preferences, which, in turn, could trap them in a cycle of poverty. We propose a new contextual feature-time-varying risk preferences induced by periodic payments - that might lead to suboptimal decisions, as another potential trigger promoting poverty. One potential way to mitigate the temporal shift in

\footnotetext{
${ }^{6}$ For example, Vellekoop (2018) shows that most housing payments (either rent or mortgage payments) are concentrated at the beginning and the end of the calendar month in the US.

${ }^{7}$ None of the existing studies explicitly focus on the elderly. See, for example, Lawrance (1991), Banerjee and Mullainathan (2010), Tanaka et al. (2010), Spears (2011), Gloede et al. (2015), Bartos et al. (2018), and Haushofer and Fehr (2019).
} 
risk preference may be to increase the frequency of payments in smaller amounts and shorten intervals between the payments. More frequent access to income allows people to smoothen their consumption patterns (Stephens and Unayama 2011), and potentially mitigate financial distress. ${ }^{8}$

Second, this study is related to the broader literature on the stability of preferences, which are generally assumed to be static economic primitives (Stigler and Becker 1977). ${ }^{9}$ The growing literature investigates whether large financial shocks, such as the Great Depression, alter risk preferences (e.g., Necker and Ziegelmeyer 2016; Guiso et al. 2018) ${ }^{10}$ Here, we emphasize that this study is conceptually distinct from these prior studies. Figure 1, which is adapted from Schildberg-Hörisch (2018, Figure 1), illustrates the conceptual framework of time-varying risk preference throughout the life course, which allows us to distinguish between permanent and temporal shifts in risk preference. Unlike previous studies that investigate the impact of a large, one-time, permanent, and unanticipated shock on baseline risk preferences (the dashed line), we evaluate the impact of the frequent, temporal, and anticipated variation in financial resources on the temporal shift around baseline risk preference (the jagged line). ${ }^{11}$ This distinction is important from a policy perspective: if the shift is permanent, policymakers can still design the policy taking the risk preference after the shock as given; however, if the shift is temporary, it is not apparent which level of risk preference they should address to design an optimal policy. ${ }^{12}$

The rest of the paper is organized as follows. Section 2 describes the data, Section 3 presents our identification strategy, Section 4 reports our findings from the HRS, Section 5 reports the supplemental findings from Japanese data, and Section 6 concludes.

\footnotetext{
${ }^{8}$ Our results also make the case for consumer protection laws such as the cooling-off period for contracts to cancel a purchase (Rekaiti and Van den Bergh 2000; Schildberg-Hörisch 2018).

${ }^{9}$ For a review of risk preferences, see Mata et al. (2018). For time preferences, see Krupka and Stephens (2013), and Meier and Sprenger (2015). For social preferences, see Carlsson et al. (2014) and Volk et al. (2012).

${ }^{10}$ A growing body of literature has suggested that experiencing not only financial crises but other large negative shocks such as natural catastrophes and conflicts too may alter one's risk preference. See Chuang and Schechter (2015) and Schildberg-Hörisch (2018) for a review.

${ }^{11}$ Alternatively, our results can be interpreted as state-dependent preferences, where preferences are a stable function of states of nature that change over time (i.e., income), as long as these states are exogenous. This would allow choices to vary with various states of nature, keeping the preference to be stable. However, it is empirically challenging to answer what constitutes an appropriate "state of nature" (Andersen et al. 2008; Dasgupta et al. 2017).

${ }^{12}$ For example, Harrison and $\mathrm{Ng}$ (2016) show that the welfare of social insurance policy is contingent on the risk preferences of the beneficiaries. If risk preference is unstable over time, what we consider as a welfareenhancing policy today could become a welfare-reducing policy in the future. See also Andersen et al. (2008), and Harrison et al. (2020).
} 


\section{Data}

\subsection{Sample selection}

Our dataset comes from the HRS, a nationally representative, biannual survey of the elderly in the US. We use data from 1994, 1998, 2000, 2002, and 2006. ${ }^{13}$ The restricted version contains the exact dates on which interviews took place, which is crucial information for our empirical strategy.

The HRS is randomly administered by the Survey Research Center at the University of Michigan to individuals over the month. During the time period covered by our data, Social Security benefits were paid out on the $3^{\text {rd }}$ of the month if it was a weekday or the first business day prior to the $3^{\text {rd }}$ in case it was a holiday or the weekend. Between 1994 and 2006, 73.1\% of Social Security beneficiaries received their checks through direct deposit, and thus had access to their benefits on pay dates (Social Security Administration 2019).

Using the exact interview dates and the known Social Security payday, we can calculate the distance between them in days. ${ }^{14}$ Then, we use this distance (in days or weeks) as the proxy variable for the respondent's financial resources. This approach enables us to compare the individual preferences of those interviewed before (i.e., those more likely to run out of money) and after (i.e., those more likely to have sufficient financial resources) the Social Security payment. In Section 3.2, we show that the interview dates are randomly assigned and thus are uncorrelated with the date on which individuals receive their Social Security paycheck.

We restrict our sample to single or coupled households with at least one member over 62, who started to receive Social Security payments before May $1997 .{ }^{15}$ Following Mastrobuoni and Weinberg (2010), we drop the widowed and divorced from the sample to ensure that an individual is not paid based on an ex- or deceased spouse's payment schedule.

Individuals from low-income households are unavoidably more dependent on Social Security benefits, and as a result, more likely to be repeatedly exposed to cyclical income

\footnotetext{
${ }^{13}$ Whereas the HRS began in 1992, we did not include data from 1992 because it included only four risk categories in the hypothetical gamble question, which we use to derive the risk preference parameter. It was expanded to six categories from 1994 onwards. After 2006, the data no longer includes the hypothetical gamble question. Note that the gamble question is only asked to new respondents and a random subsample of returning respondents. After the sample restriction is imposed, no observations are left in the data from 2004. ${ }^{14}$ We verified with the HRS team that $92.4 \%$ of completed respondents start and end on the same date, so the measurement errors from the difference in interview dates and reply dates are minimal.

${ }^{15}$ For those who started receiving Social Security payments after May 1997, the payday changes to the second, third, or fourth Wednesday, depending on the beneficiary's birthday.
} 
fluctuations. Appendix Figure A1 shows that individuals with high dependency on Social Security income are indeed poor. The figure plots the relationship between the share of Social Security income among total household income on the $x$-axis and the total household income on the $y$-axis. It clearly shows that high dependence on Social Security is driven by low total household income (i.e., the denominator of the share) since the amount of Social Security income (i.e., the numerator of the share) does not vary much across individuals. For that reason, we divide the sample into individuals from households in which the share of Social Security income among total household income is above 50\% (more dependent and poor/low-income), or $43 \%$ of the full sample, and below 50\% (less reliant and rich/high-income). ${ }^{16}$ Similar approaches are taken by Stephens (2003), and Mastrobuoni and Weinberg (2009). Later, we show that our results are qualitatively robust even when the high/low dependence thresholds are changed to $40 \% / 60 \%$.

\subsection{Outcome: Risk tolerance}

Here, we describe how we measure and construct risk preference. The HRS uses hypothetical gambles over lifetime income to elicit risk attitudes. Respondents choose between a safe and a risky job in hypothetical scenarios. With equal chances, a risky job will double the income or cut monthly income by a specific fraction $(1 / 10,1 / 5,1 / 3,1 / 2$, and $3 / 4)$. Varying the size of downside risk on the monthly income in subsequent questions refines the measure of risk preference (see Appendix Table D1 for the questionnaires).

We follow Barsky et al. (1997) and Kimball et al. (2008) to derive the risk tolerance parameter $\theta$ for each individual. Specifically, we assume that constant relative risk aversion (CRRA), $U(W)=\frac{W^{1-1 / \theta}}{(1-1 / \theta)}$, well approximates individuals' utility over lifetime income, and that the coefficient of relative risk tolerance $\theta=-U / w U^{\prime \prime}$ may differ across individuals (Pratt 1964). Appendix Table A1 provides the relationship between the six gamble response categories and the

\footnotetext{
${ }^{16}$ Whereas Mastrobuoni and Weinberg (2009) limit their sample to individuals from households in which Social Security income makes up at least $80 \%$ of total household income, the share in their sample is $41 \%$, which is roughly similar to the share of our above- $50 \%$ sample (43\%). The more stringent $80 \%$ criteria only applies to $17.2 \%$ of our sample $(\mathrm{N}=211)$, which substantially shrinks our sample size. This contrast indicates that our sample is relatively less reliant on Social Security benefits than that of Mastrobuoni and Weinberg (2009), who use the Continuing Survey of Food Intake by Individuals, 1994-1996.
} 
corresponding downside risks that the individual accepts or rejects. ${ }^{17}$ Importantly, we later show that we do not need to rely on this particular functional form; our results are robust using the ordinal measure of risk tolerance in Section 4.2. Panel (a) of Appendix Figure A2 shows the frequency distributions of gamble responses. The figure reveals substantial heterogeneity in risk attitudes. The figure also shows that most individuals are unwilling to take risks and roughly half of the respondents belong to the lowest risk category (category 1).

Even though the gamble response is hypothetical, there are several reasons to justify the use of this variable to examine the stability of risk preference (Camerer and Hogarth 1999). First, Barsky et al. (1997) show that this risk measure, obtained by hypothetical gamble questions in the HRS, is correlated with actual risk-taking behaviors such as smoking, drinking, and ownership of financial assets. Second, the stakes of the gambles over lifetime income are large, which is necessary to properly measure risk preference within the expected-utility framework, as discussed in Rabin (2000). Third, Dohmen et al. (2011) validate the use of hypothetical choice questions by comparing them to incentivized lottery questions. Finally, the gambles over lifetime income are clearly framed as gambles over long-run risks, not small-to-moderate gambles that can be reimbursed immediately. This mitigates the concern that our results do not reflect the change in risk preference per se but reflect, rather, the liquidity constraints that restrict individuals' choices (Haushofer and Fehr 2014). ${ }^{18}$ For these reasons, this risk tolerance measure in the HRS was widely used in previous studies (e.g., Barsky et al. 1997; Kimball et al. 2008; Sahm 2012).

Table 1 presents descriptive statistics for the analysis sample. The first row in Table 1 shows that the mean of the risk tolerance parameter in the sample is 0.540 with a standard deviation of 0.834 . The average age is 69.3 years, and $92 \%$ of the sample are married. Roughly half $(50.4 \%)$ are female.

\footnotetext{
${ }^{17}$ The category numbers are higher as the individual's willingness to accept income risk increases, and thus the corresponding risk tolerance parameter is larger. We use the midpoint of the intervals of risk tolerance parameters between the two adjacent risk categories. As a robustness check, we construct an ordinal risk tolerance measure that does not rely on the interval of the risk categories as described in Section 4.2. ${ }^{18}$ Furthermore, if individuals choose the safe option to alleviate liquidity constraints before payday, it would go against our finding that individuals become risk-tolerant before payday.
} 


\section{Identification strategy}

\subsection{Econometric model}

We first organize the interview dates in relation to the $3^{\text {rd }}$ of each month. For ease of explanation, we use the $3^{\text {rd }}$ of the month, but this is adjusted by a few days if it is not a weekday. Then, we construct each synthetic month around the $3^{\text {rd }}$ of the month ranging from -14 to +13 days, limiting the sample to 14 days around payday (Stephens 2003). Importantly, we can exactly identify before and after payday without errors as we know both the exact payday as well as the interview date. ${ }^{19}$

Given this structure of the data, the econometric model is written as

$$
Y_{i}=\sum_{k \neq+1}^{k=-1,-2,+2} \beta_{k} 1(\text { week }=k)+\gamma X_{i}^{\prime}+\delta_{F E}+\varepsilon_{i}, \quad[1]
$$

where $Y_{i}$ is the outcome for individual $i .1($ week $=k)$ is a dummy that takes one if the week belongs to two weeks before $(k=-2)$, a week before $(k=-1)$, or two weeks after $(k=+2)$ the payday (Stephens 2003, 2006; Evans and Moore 2011, 2012). We later show that our results are robust by narrowing the sample to just around the payday and using the daily interval instead of week aggregation, which gives more statistical power. Our reference week is the week immediately after payday $(k=+1)$. Since we are particularly interested in the effect of financial strain on risk preference, our main coefficient of interest is $\beta_{-1}$, the coefficient from the week before the payday. This coefficient captures the difference in outcomes before and after payday. The estimates on other week dummies help us understand the within-month dynamics of change in outcomes in the longer term, which is not possible with only one-week interval data (cf. Carvalho et al. 2016). $X_{i}^{\prime}$ denote the individual characteristics, namely age, gender, household size, self-reported health indicators, highest years of schooling, marital status, race, retirement status, and Metropolitan statistical areas (MSA) status dummies. We also include a number of fixed effects (FEs), $\delta_{F E}$, namely day of the week FEs, year FEs, month FEs, and year-month FEs. $\varepsilon_{i}$ is an error term. We estimate equation [1] by OLS unless specified otherwise.

The change in financial resources around payday could affect one's risk preference in two opposite ways. On the one hand, limited financial resources before payday could increase the marginal utility of consumption, and hence reduce one's willingness to take risks. This

\footnotetext{
${ }^{19}$ This setting allows us to avoid the potential endogeneity of the survey response timing in Carvalho et al. (2016). See Mani et al. (2020) for further discussion on this point.
} 
observation is in line with association studies showing that the poor tend to be risk-averse (Guiso and Paiella 2008; Dohmen et al 2011). On the other hand, the literature on social comparison argues that the sense of relative deprivation tends to increase one's willingness to take risks, as individuals strive to catch up to their comparison standards (Mishra et al. 2015; Payne et al. 2017). For example, Haisley et al. (2008) show that increased feelings of poverty among lowincome individuals induce them to take more risks (buying more lottery tickets) to correct for their low-income status. ${ }^{20}$ If a lack of financial resources before payday increases one's feelings of being poorer than others or than one's desired state, one might be more willing to take risks. Finally, as we discuss in Section 4.3, the empirical evidence relating to the impact of the association between stress/depression and financial worries on risk preference is very mixed. Therefore, we view that the direction of change in risk preference on payday is ultimately an empirical question.

\subsection{Randomization tests}

The key to our identification strategy is that the interview dates are randomly assigned to individuals, and thus are uncorrelated with the date on which individuals receive their Social Security paycheck. To test that the interview dates are exogenous to financial situations, following Mastrobuoni and Weinberg (2009), we estimate equation [1], where outcomes are predetermined variables in the dataset, namely age, gender, years of schooling, and indicators for being married, retired, in good health, in poor health, and black. We also test for differences in indicators for whether a household is located in the Northeast, Midwest, South, or West.

Table 2 presents the results of the randomization tests for the entire sample in panel (a), and separately for individuals from households in which the share of Social Security income among total household income is above and below 50\% in panels (b) and (c), respectively. The table presents F-tests of the joint null hypothesis that each of the estimates on the four-week dummies is equal to zero with corresponding p-values. Table 2 shows that only regional dummies are ever statistically different at the $5 \%$ levels, potentially reflecting that the survey

\footnotetext{
${ }^{20}$ Relatedly, risk-sensitivity theory (RST) suggests that individuals shift from risk-aversion to risk-proneness in situations of higher perceived need, where need refers to a disparity between an individual's present and desired states (Pietras and Hackenberc 2001; Mishra and Lalumière 2010). This theory from biology was originally developed to explain animal foraging behaviors. See Mishra (2014) for a review.
} 
was administered at different times for each region. In our regressions, we control for all these predetermined variables. $^{21}$

\section{Results}

\subsection{Graphical evidence}

We first present our graphical evidence. Figure 2 plots the measure of risk tolerance, $\theta$, for individuals for whom the share of Social Security income is above 50\% in panel (a) and below $50 \%$ in panel (b), with 2-day bins around the payday. Panel (a) clearly shows that the risk tolerance parameter is discontinuously higher just before the payday, indicating that respondents are more risk-tolerant just before payday. Interestingly, within the course of the month, the risk tolerance parameter increases monotonically, indicating that respondents gradually become more risk tolerant as they become more financially distressed. On the contrary, we do not see such a systematic pattern for below-50\% respondents in panel (b), suggesting that the results for the above-50\% respondents in panel (a) are indeed driven by the availability of Social Security income.

\subsection{Basic results}

Here, we formally present the results from estimating equation [1]. The results are shown in Table 3. Column (1) of Table 3 shows the estimate for the respondents with high dependence on Social Security income (i.e., above- $50 \%$ respondents). The before-payday week $(k=-1)$ is associated with a 0.352 increase in risk tolerance. Since the standard deviation of the risk tolerance parameter is 0.816 in this sample, this represents a $0.43 \mathrm{SD}$ increase in risk tolerance. Other week dummies are not statistically significant at conventional levels. On the contrary, column (2) of Table 3 shows no such pattern among respondents who rely less on Social Security income. ${ }^{22}$ Taken together, these results indicate that payment of Social Security plays a role in

\footnotetext{
${ }^{21}$ One remaining issue is the sample selection: it could be problematic if individuals with higher or lower risk tolerance are symmetrically more likely to be selected into the survey in a particular week. Whereas testing the issue of sample selection requires risk tolerance measures on respondents who are not interviewed (which do not exist), it is reassuring that the observable characteristics among those who are interviewed are balanced. See Harrison et al. (2020) for discussions on endogenous sample selection and attrition.

${ }^{22}$ The p-value of the difference in estimates on a week before payday (week -1) between above-50\% sample in column (1) and below-50\% sample in column (2) is 0.106 .
} 
elevated risk tolerance before payday.

Robustness- - Our results on risk tolerance are robust to different ways of defining high dependence on Social Security income. Table 4 presents the results where we define high dependence by $40 \%$ and $60 \%$ shares of Social Security income among total household income, which correspond to $56 \%$ and $31 \%$ of the overall sample, respectively.

For ease of comparison, column (1) in Table 4 replicates the baseline estimates from column (1) from Table 3, where we define high dependence by a $50 \%$ share of Social Security income (sample share of $43 \%, \mathrm{~N}=527$ ). When we define high dependence by $40 \%$ share ( $\mathrm{N}=$ 700 ), the estimates on a week before payday stay statistically significant at the $5 \%$ level. Once we change the threshold to $60 \%(\mathrm{~N}=380)$, statistical significance drops to a $10 \%$ level; however, this estimate is similar to the baseline specification in column (1). Appendix Table A2 reports the results for those below the $40 \%$ and $60 \%$ thresholds, which reveal no changes in risk preference before payday, further supporting our null effect for those who rely less on Social Security income.

Importantly, our results are not driven by the cardinality of our risk preference measure, as shown in Table 5. First, we construct an ordinal measure, which is one if respondents choose the most or second-most risk-tolerant categories (categories 5 and 6 ) in the gamble question, and zero otherwise. Column (1) of Table 5 shows that our results are robust using this ordinal measure. Next, column (2) presents the estimates of the ordered probit model; our results are again robust to another ordinal measure. Finally, as a separate note, column (3) shows that our results are robust to the interval regression, suggesting that the arbitrary choice of midpoints in constructing a cardinal measure of risk preference plays little role.

We also estimate the regression discontinuity (RD) model as a part of our robustness check, using the distance from the payday (measured in days) as a running variable. ${ }^{23}$ Appendix Table A3 summarizes the results. Rather surprisingly, we obtain statistically significant results $(p<0.01)$, even with this small sample size. Since we only use the sample in the vicinity of the payday, the RD estimates are larger than our baseline OLS estimates. We prefer our OLS approach over the RD design because we are not only interested in single days on either side of payday, but the entire profile of the risk tolerance parameter throughout the month. Nonetheless, it is reassuring that our results are robust to this different specification.

\footnotetext{
${ }^{23}$ We follow Calonico et al. (2014) to choose the data-driven optimal bandwidth.
} 
Placebo- We run the same specification for the samples among which we do not expect to find effects. Appendix Table A4 reports the results. In particular, we examine two samples: (i) people aged 50-61 years who are younger than the eligibility age of 62 for Social Security, and (ii) people aged 62 and over who do not yet receive Social Security benefits. It is reassuring that none of the estimates on the week before payday are statistically significant or economically large.

\subsection{Possible mechanism}

Thus far, we provide robust evidence that individuals from households with a heavy dependence on Social Security become more risk-tolerant just before payday. To probe the mechanism behind this phenomenon, we examine the cognitive function and mental health of beneficiaries before and after payday.

Cognitive function-. A number of studies present the link between cognition and risk preference (e.g., Frederick 2005; Burks et al. 2009; Dohmen et al. 2010; Benjamin et al. 2013). More recently, Mullanaithan and Shafir (2013), among others, argue that poverty reduces cognitive capacity because poverty-related concerns consume mental resources (or bandwidth), which also degrades the quality of decisions. For example, Mani et al. (2013) find that the cognitive function of farmers in India diminishes before the harvest, when they are poor, compared with after harvest, when they are wealthier. In contrast, Carvalho et al. (2016) do not find supportive evidence that financial strain impedes cognitive function and worsens decisionmaking.

Interestingly, Lichand and Mani (2019) argue that the discrepancy between Mani et al. (2013) and Carvalho et al. (2016) can be explained by (i) the lack of uncertainty in payment timing and amounts in Carvalho et al. (2016), and/or (ii) the higher income levels of the US respondents relative to the Indian farmers in Mani et al. (2013). Since the timing and amount of Social Security are known to the beneficiaries, the lack of cognitive decline in our case could also be explained by the lack of uncertainty.

We define cognition status based on a 27-point score composed of the word recall, serial sevens, and backward counting tests. Panel (b) of Appendix Figure A2 shows the frequency distributions of these 27-point cognition scores. Following Ayyagari and Frisvold (2016), scores between 12 and 27 are classified as normal; between 7 and 11 as cognitive impairment, not 
dementia (CIND); and between 0 and 6 as dementia. Among the households whose income share of Social Security is above $50 \%$, the fractions of CIND and dementia are $20.8 \%$ and $3.4 \%$ respectively (see Table 6).

Table 6 reports the estimates from equation [1], where the outcome is a dummy for normal, CIND, and dementia in each column. None of the estimates in Table 6 are statistically significant at the conventional levels. Appendix Table A5 repeats the same exercises for the sample of individuals whose share of Social Security among total household income is above $40 \%$ and $60 \%$, and we do not find any before-after payday changes in any outcomes. Thus, cognitive load does not seem to drive our results, at least in our setting and within our measures of cognitive function (cf., Raven's Matrices test).

Mental status - . Next, we look at mental status or mood. Mental health could be susceptible to income fluctuation as financial strain is often associated with higher levels of stress and depression — see Haushofer and Fehr (2014) and Ridley et al. (2020) for a review. ${ }^{24}$ The empirical evidence of the impact of stress/depression on risk preferences is, however, mixed at best (Kremer et al. 2019). ${ }^{25}$ The evidence from these studies is less informative for our setting because most of them are conducted in the lab, and most importantly, examine the effect of onetime acute stress rather than the moderate, temporary, and repeated stress under study. Note that cognitive function and mental status are not mutually exclusive. Depressed individuals might be more likely to be cognitively impaired or vice versa.

The HRS asks a question about depression. Specifically, it asks whether the person felt depressed much of the time during the past week, and the respondent answers "yes/no." We create a dummy that takes the value of one if the person chooses "yes." Since the reference period of this question is a week from the survey date, we subtract seven days from the original distance in days and reconstruct the week dummies in equation [1] accordingly.

Table 7 presents the results for depression. Column (1) presents the OLS estimates for

\footnotetext{
${ }^{24}$ The literature from psychology emphasizes that psychological well-being affects individuals' risk preferences (see Lerner et al. 2015 for a review).

${ }^{25}$ Some studies find that stress increases risk aversion (Mather et al. 2009; Porcelli and Delgado 2009; Kandasamy et al. 2014; Cahlíková and Cingl 2017), whereas others find it increases risk tolerance (Starcke et al. 2008; Putman et al. 2010; Pabst et al. 2013a, 2013b; Buckert et al. 2014; Cueva et al. 2015; Bayer et al. 2019) or has no significant effect (Delany et al. 2014; Sokol-Hessner et al. 2016). Cobb-Clark et al. (2020) do not find any differences in behavioral risk preferences between the mentally well and the depressed but they also find that depression is related to people's stated risk preferences and risk-taking behaviors, which are context-specific.
} 
individuals whose Social Security share is above $50 \%$. Individuals who are heavily reliant on Social Security are $8.1 \%$ more likely to feel depressed a week before, than a week after, payday $(\mathrm{p}<0.10)$. Since the mean is only $15.3 \%$, we also report the estimates from the non-linear model, namely Probit, in column (2), and find similar marginal effects. ${ }^{26}$ Columns (3)-(6) repeat the same exercises for the sample of individuals whose share of Social Security among total household income is above $40 \%$ and $60 \%$, and find that the biggest impact is observed when the income share is set above the $60 \%$ threshold in columns (5) and (6).

To examine whether mental health is the potential driving factor of change in risk preference, we also examine the mental health of those who should not be much affected: those whose income share of Social Security is below $50 \%$ and whose risk preferences do not change around payday. Appendix Table A6 shows that those who rely less on Social Security are not depressed before payday.

Taken together, although they are at best suggestive, these contrasting results between high vs. low dependence imply that one of the many underlying mechanisms for the increased risk tolerance before payday may be the deterioration of mental status. Whereas the question on depression in the HRS refers to the week prior to the interview date, risk tolerance is measured on the interview date; as a result, the respondents who answered each question are off by one week. This, unfortunately, precludes us from conducting a mediation analysis in our acrosssubjects design to examine whether depression is the underlying mediator for changes in risk preference.

Our results on risk preference differ from the seminal work by Carvalho et al. (2016), which also exploits randomness in survey dates and compares preference, cognitive function, and decision-making shortly before and after payday among US low-income respondents. They find that while the poor with liquidity constraints behave as if they are present-biased before payday, they did not find any before-after differences in risk preference and cognitive function performance. Although the sign of their estimates on the CRRA parameter was the same as ours (see Table 4 in Carvalho et al. 2016), their estimate was far from statistically significant.

The key advantage in our setting is that our nationally representative sample - albeit only comprising the elderly —includes both rich respondents who rely less on Social Security as well

\footnotetext{
${ }^{26}$ The WHO (2017), in "Mental health of older adults," states that approximately 15\% of adults aged 60 and over suffer from a mental disorder, which is close to the $15.3 \%$ in our data.
} 
as poor respondents more reliant on it, unlike Carvalho et al. (2016), who exclusively focus on the poor. ${ }^{27}$ The contrasting results on depression between the respondents with high vs. low dependence on Social Security imply that mental health plays some role. ${ }^{28} \mathrm{We}$ will revisit this issue using data from Japan in the next section. Relatedly, another potential reason is that we exclusively focus on the elderly, ${ }^{29}$ who could be more mentally vulnerable, and sensitive to even temporary and anticipated income fluctuation. ${ }^{30}$ In this regard, our results are very close to the findings of Dalton et al. (2020); the study is rare in that it collects both risk preference measures as well as mental health outcomes in a field setting. They find that owners of small retail businesses in Vietnam exposed to financial worries are more stressed and behave less risk-averse than those assigned to placebo treatment.

\section{Supplemental evidence from Japan}

To assess external relevance, we also examine whether the same results hold among the elderly in Japan. The public pension in Japan is paid on the 15 th of every even month. ${ }^{31}$ Stephens and Unayama (2011) show that benefit receipt of public pension significantly affects household consumption in Japan.

Risk preference-. We again compare individuals' risk preferences before and after payday. This is more than a simple replication exercise, since the US and Japan have very different baseline risk preferences. Falk et al. (2018) collected individual preferences from 80,000 people in 76 countries and showed that Japan is one of the most risk-averse countries (\#6), whereas the US is on the other side of the spectrum $(\# 52)^{32}$ — see Figure 1 in Falk et al. (2018).

\footnotetext{
${ }^{27}$ Carvalho et al. (2016) exclusively focus on individuals in low-income households (annual household income below $\$ 40,000)$ in the US.

${ }^{28}$ To our knowledge, Carvalho et al. (2016) did not report the results on mental health.

${ }^{29}$ The average age in Carvalho et al.'s (2016) in Study 1 and 2 is 49 and 56, respectively, which is much younger than the average of 69 years in our sample.

${ }^{30}$ For example, in addition to common stressors, the elderly may experience life stressors particular to later life, such as significant ongoing loss in capacity and a decline in functional ability. Furthermore, the social isolation during the COVID-19 pandemic could exacerbate the mental vulnerability of the elderly (Armitage and Nellums 2020).

${ }^{31}$ If the $15^{\text {th }}$ in the month falls on a weekend or holiday, benefits are paid on the first business day before the $15^{\text {th }}$, as in the case of Social Security payments in the US.

${ }^{32}$ Authors' calculation based on the data here: https://www.briq-institute.org/global-preferences/rankings\#2-0$\underline{0}$ (last accessed on 03/10/2020).
} 
Our data comes from the Japanese Study of Aging and Retirement (JSTAR) from 20072013. JSTAR, beginning in 2007, is modeled after the HRS, and interview surveys are conducted biennially. Respondents are those aged over 50 from 10 municipalities. ${ }^{33}$ The restricted version contains the exact dates on which the interviews took place.

Risk tolerance in JSTAR is measured by the hypothetical question on the choice of income between two scenarios, which is conceptually similar to the lifetime income gamble question in the HRS. The safe option guarantees a $20 \%$ increase in income, whereas the risky option increases income by either $50 \%$ or $5 \%$ with a specific probability. Varying the chance of the downside risk on risky options refines the measure of risk preference. The exact wording of the questionnaire is presented in Appendix Table D2. To be consistent with the HRS, we derive the risk tolerance parameter $\theta$ in the same way, assuming the CRRA utility function. Again, higher values indicate more risk tolerance. ${ }^{34}$

Appendix Table B2 presents the descriptive statistics of the JSTAR sample. Interestingly, JSTAR respondents rely more heavily on pension benefits than HRS respondents. The average share of public pension in total household income in JSTAR (64.2\%) is even higher than the threshold of $50 \%$ share in HRS. Thus, we do not divide the sample by the share of the public pension here to maximize the statistical power $(\mathrm{N}=2,728)$. Following the HRS analysis, to avoid the influence of other income sources, we restrict the sample to households in which at least one person receives the public pension and there are no cohabiting children or parents. The average age is 68.5 years, which is very similar to the HRS sample (69.3 years). Some $80.3 \%$ are married; roughly half $(51.0 \%)$ are female.

Since the payment of the public pension in Japan is every two months instead of every month, we slightly modify equation [1] to include more week dummies as follows:

\footnotetext{
${ }^{33}$ The data is collected by the Research Institute of Economy, Trade, and Industry (RIETI), Hitotsubashi University, and University of Tokyo. See https://www.rieti.go.jp/en/projects/jstar/ for the details of JSTAR. These municipalities are Takikawa City in Hokkaido Prefecture, Sendai City in Miyagi Prefecture, Adachi Ward in the Tokyo metropolis, Kanazawa City in Ishikawa Prefecture, Shirakawa Town in Gifu Prefecture, Naha City in Okinawa Prefecture, Tosu City in Saga Prefecture, Chofu City in the Tokyo metropolis, Tondabayashi City in Osaka Prefecture, and Hiroshima City in Hiroshima Prefecture.

${ }^{34}$ Appendix Table B1 provides the relationship between the eight income response categories and the downside risks. The larger category numbers indicate that individuals are willing to accept higher income risk, and thus the corresponding risk tolerance parameter is larger. Appendix Figure B1 presents the frequency distributions of risk categories, revealing substantial heterogeneity in risk attitudes.
} 


$$
Y_{i}=\sum_{k \neq+1}^{k=-1,-2,-3,-4,+2,+3,+4} \beta_{k} 1(\text { week }=k)+\gamma X_{i}^{\prime}+\delta_{F E}+\varepsilon_{i}, \quad[1]
$$

Again, our reference week is the week immediately after payday $(k=+1)$, and our main coefficient of interest is $\beta_{-1}$, the coefficient for the week before payday. In addition to the FEs included in equation [1], the two-month intervals between paydays allow us to include week-ofthe-month FEs, because these data include the calendar months when the public pension is not paid (odd months), which is impossible in the case of the US. This setting partially mitigates the concern that the results in the US are driven by other events at the beginning of the calendar month, such as housing payment (Vellekoop 2018).

Appendix Table B3 presents the results from testing the randomness of the interview dates. Specifically, we run equation [1]' on the predetermined variables in the dataset. The table reports the F-tests and corresponding p-values of the null hypothesis that each of the estimates on the eight-week dummies is equal to zero. Except for age, none of the 11 estimates is statistically significant at the $5 \%$ level. ${ }^{35}$ In our regressions, we control for all these predetermined variables.

We first present our graphical evidence. Appendix Figure B2 plots the measured risk tolerance with 2-day bins around the payday. As the interval between payments is two months, our synthetic month around the $15^{\text {th }}$ of the month ranges from -28 to +27 . The figure shows that the risk tolerance parameter is discontinuously higher just before payday, indicating that respondents are more risk-tolerant before payday in Japan as in the US.

Table 8 reports the results from estimating equation [1]' without any individual controls in column (1) and with controls in column (2). Column (1) shows that the before-payday week $(k=$ $-1)$ is associated with the increase of risk tolerance by $0.056(\mathrm{p}<0.05)$. This represents a $28.7 \%$ increase in risk tolerance of the standard deviation (0.195). None of the other week dummies are statistically significant, suggesting that temporal shift in risk preference is concentrated within one week prior to payday. Adding individual controls in column (2) barely changes the estimate on a before-payday week dummy, supporting the success of the randomization of interview dates.

Appendix Table B4 reports the results of other specifications and reassuringly, our results are fairly robust. Appendix Table B5 presents the results of placebo checks using two samples: (i) people aged 50-59 years who are younger than the eligibility age of 60 for public pension in

\footnotetext{
${ }^{35}$ For privacy reasons, geographical information is not available in JSTAR.
} 
Japan, ${ }^{36}$ and (ii) people aged 60 and above, who do not yet receive pension benefits. Again, it is reassuring that none of the estimates on the week before payday are statistically significant or economically large. Whereas the country and the sample period are different in the HRS and JSTAR, we find similar patterns in both data, which strengthens the external validity of our results.

Revisiting potential mechanisms - Ideally, we would want to examine whether we can observe the same patterns on depression in JSTAR as we find in the HRS. Unfortunately, JSTAR's depression measure is collected by self-report questionnaires, instead of face-to-face interviews, and as a result, the exact dates of data entry are unknown.

Therefore, we resort to another dataset, the Japanese General Social Surveys (JGSS), which is modeled after the General Social Surveys in the US. ${ }^{37}$ Again, the restricted version contains the exact dates on which interviews took place. We use the data from 2008, which contains the two key variables we examine below (financial anxiety and self-perceived social status). ${ }^{38}$ Appendix Table $\mathrm{C} 1$ presents the descriptive statistics of the JGSS sample. To make it comparable to the JSTAR sample, we restrict the sample to individuals over 60 , whose main source of income is the pension benefit. ${ }^{39}$ Appendix Table $\mathrm{C} 2$ reports the results from testing the randomness of the interview dates. Except for one, none of the 11 estimates are statistically significant at the 5\% level. Again, in our regressions, we control for all these predetermined variables.

We examine financial anxiety, as this is most closely related to the mental status, given that there is no direct question on depression in JGSS. Indeed, financial strain is often associated with higher levels of stress and depression (Ridley et al. 2020). Specifically, to the question "Do you feel anxious about your economic situation in the future?", we create a dummy that takes the

\footnotetext{
${ }^{36}$ Strictly speaking, the Pension Reform Act implemented in 2001 raises the pension eligibility age from 60 to 65 by one year every two years for the fixed part of the pension benefit from 2001 (Kondo and Shigeoka 2017). However, for most of the respondents in our data, the pension eligibility age is 60 .

${ }^{37}$ JGSS is carried out by Osaka University of Commerce, in collaboration with the Institute of Social Science at the University of Tokyo since 2000. See https://jgss.daishodai.ac.jp/english/surveys/sur top.html for the details. The subject population consists of men and women aged 20 to 89 as of September 1 of the particular survey year; they are selected using a stratified 2-stage sampling method. The stratification divides Japan into six blocks - Hokkaido/Tohoku, Kanto, Chubu, Kinki, Chugoku/Shikoku, and Kyushu — and further divides those into four groups: largest cities, cities with populations of 200 thousand or more, cities with populations under 200 thousand, and towns/villages.

${ }^{38}$ Unfortunately, HRS collected financial strain and subjective social status in the leave-behind questionnaires; thus, the exact dates of data entry are unknown.

${ }^{39}$ JGSS does not collect the amount of pension benefit but collects information on the main source of income.
} 
value of one if the respondents choose either "I feel very anxious" or "I feel somewhat anxious," or zero otherwise. ${ }^{40}$ See panel (a) in Appendix Figure $\mathrm{C} 1$ for the frequency distributions of responses.

Panel (a) in Appendix Figure C2 plots this outcome with 2-day bins around the payday. Note that since the spell of interview dates is short in JGSS, we restrict the sample to windows of 14 days, instead of 28 , from payday. ${ }^{41}$ The figure demonstrates that the fraction of financially anxious individuals is discontinuously higher just before payday, which is similar to the finding on depression in the US. Columns (1) and (2) report the results from estimating equation [1], where the outcome is the financial anxiety, and confirms the graphical findings; column (1) from OLS shows that the before-payday week $(k=-1)$ is associated with a 20.6 percentage points increase in financial anxiety $(\mathrm{p}<0.05)$, and column (2) from probit presents similar results.

JGSS allows us to explore another potential mechanism discussed in the literature on risky choice and relative deprivation/social comparison. The idea behind the literature in our context is that scarce financial resources before payday makes people feel relatively deprived compared to others; it induces one to take more risks to catch up to the comparison. For example, Haisley et al. (2008) show that enhanced feelings of poverty among low-income individuals induce them to take more risks. Similarly, Mishra et al. (2015) and Payne et al. (2017) show that higher inequality increases risk-taking due to upward social comparisons.

Specifically, the JGSS asks a question of self-placement on a 10-point social status scale: "If we were to divide the contemporary Japanese society into the following ten strata, which would you say you belong to?" We create a dummy that takes the value of one if the respondents choose the lowest and second-lowest categories (categories 9 and 10) and zero otherwise. Panel (b) in Appendix Figure C2 shows that the fraction of individuals who view themselves as belonging to a low social status, is discretely higher just before payday. Column (3) of Table 9 shows that the before-payday week $(k=-1)$ is also associated with 7.6 percentage points increases in low self-perceived social status $(\mathrm{p}<0.05)$. This effect is substantial, given that the mean of the outcome is $9.9 \%$. Almost identical results are obtained from probit in column (4). ${ }^{42}$ Taken individually, each piece of evidence in the US and Japan is not sufficient to pin

\footnotetext{
${ }^{40}$ We obtain similar results if the outcome takes the value of one only for "I feel very anxious" (not shown).

${ }^{41}$ The interview dates span from Oct. 1 to Dec. 22 in 2008; pension paydays are Oct. 15 and Dec. 15.

${ }^{42}$ See Appendix Table C3 for the other specification, and Appendix Table C4 for the placebo checks. These tests also support the interpretation of our results.
} 
down the underlying mechanism of temporary fluctuation in risk preference around payday, since we cannot formally run the mediation analysis. However, taken together, the evidence suggests that the mental state and/or feeling of relative deprivation may play certain roles. Indeed, there are interplays between mental state and relative deprivation. Relative deprivation is, in fact, shown to negatively affect both physical and mental health (e.g., Eibner et al. 2004; Jones and Wildman 2008; Daly et al. 2013). We do not, however, claim that these are the only mechanisms, and we are well aware that many alternative explanations could be consistent with our findings. While it is beyond the scope of this paper to identify the exact mechanism, it leaves ample avenues for future research.

\section{Conclusion}

We evaluate the impact of income fluctuations on measured risk preference among the elderly by exploiting the periodic payday cycles of Social Security benefits in the US and public pension benefits in Japan. In both countries, we find evidence of temporary but systematic variation in risk preference around payday, at least among the samples of older adults in the 1990s in the US, and in the 2000s in Japan. To our knowledge, this is the first study to show that risk preference may not be temporally stable. This temporal shift in risk preference around payday indicates that optimal decisions made before payday may turn into non-optimal decisions afterward.

It is important to stress that these results on risk preference have been found in countries with very different baseline risk preferences (the US and Japan). This suggests that evidence from this study may apply more generally to a broad set of countries with different levels of underlying risk preference. Relatedly, our results indicate that even commonly occurring income fluctuations of realistic magnitude might temporarily alter individual risk preferences.

This study provides several avenues for future research. First, whereas our across-subjects design still allows us to investigate the temporal stability of aggregate risk preference, it is important from a policy perspective to identify the characteristics of individuals who exhibit unstable risk preference, using a within-subject design. Second, more research is needed to understand the underlying mechanisms for such temporal shifts in preference. Finally, examining whether our results hold in a different subject pool (e.g., non-elderly), and different magnitudes of temporal financial distress (e.g., intervals) with various levels of uncertainty, would be an 
interesting extension. For instance, the pension is paid every two weeks in Australia. As periodic payment of welfare programs, pensions, and salaries is prevalent in many countries, there is ample opportunity to apply a similar research design, and investigate whether a similar pattern in risk or other preferences (e.g., time and social preferences) can be observed in other settings.

\section{References}

Andersen, Steffen, Glenn W. Harrison, Morten I. Lau, and E. Elisabet Rutström. (2008) "Lost in state space: Are preferences stable?" International Economic Review, 49(3): 1091-1112.

Armitage, Richard, and Laura B Nellums. (2020) "COVID-19 and the consequences of isolating the elderly." Lancet Public Health, 5(5): 296.

Ayyagari, Padmaja, and David Frisvold. (2016) "The impact of social security income on cognitive function at older ages." American Journal of Health Economics, 2(4): 463-488.

Banerjee, Abhijit V., and Sendhil Mullainathan. (2010) "The shape of temptation: Implications for the economic lives of the poor." Unpublished Manuscript.

Barsky, Robert B., F. Thomas Juster, Miles S. Kimball, and Matthew D. Shapiro. (1997) "Preference parameters and behavioral heterogeneity: An experimental approach in the Health and Retirement Study." Quarterly Journal of Economics, 112(2): 537-579.

Bartoš, Vojtěch, Michal Bauer, Julie Chytilová, and Ian Levely (2018) "Psychological effects of poverty on time preferences." The Economic Journal, forthcoming.

Bayer, Ya'akov M., Zeev Shtudiner, Oxsana Suhorukov, and Nimrod Grisaru. (2019) "Time and risk preferences, and consumption decisions of patients with clinical depression." Journal of Behavioral and Experimental Economics, 78: 138-145.

Benjamin, Daniel J., Sebastian A. Brown, and Jesse M. Shapiro. (2013) "Who is 'behavioral'? Cognitive ability and anomalous preferences." Journal of the European Economic Association, 11: 1231-1255.

Buckert, Magdalena, Christiane Schwieren, Brigitte M. Kudielka, and Christian J. Fiebach. (2014) "Acute stress affects risk taking but not ambiguity aversion." Frontiers in Neuroscience, 8: 82.

Burks, Stephen V., Jeffrey P. Carpenter, Lorenz Goette, and Aldo Rustichini. (2009) "Cognitive skills affect economic preferences, strategic behavior, and job attachment." Proceedings of the National Academy of Sciences, 106(19): 7745-7750.

Cahlíková, Jana, and Lubomír Cingl. (2017) "Risk preferences under acute stress." Experimental Economics, 20(1): 209-236.

Calonico, Sebastian, Matias D. Cattaneo, and Rocio Titiunik. (2014) "Robust nonparametric confidence intervals for regression-discontinuity designs." Econometrica, 82(6): 2295-2326.

Camerer, Colin F., and Robin M. Hogarth. (1999) "The effects of financial incentives in experiments: A review and capital-labor-production framework." Journal of Risk and Uncertainty 19: 7-42.

Carlsson, Fredrik, Olof Johansson-Stenman, and Pham Khanh Nam. (2014) "Social preferences are stable over long periods of time." Journal of Public Economics, 117: 104-114.

Carvalho, Leandro S., Stephan Meier, and Stephanie W. Wang. (2016) "Poverty and economic decision-making: evidence from changes in financial resources at payday." American Economic Review, 106(2): 260-284. 
Chuang, Yating, and Laura Schechter. (2015) "Stability of experimental and survey measures of risk, time, and social preferences: A review and some new results." Journal of Development Economics, 117: 151-170.

Cobb-Clark, Deborah A., Sarah C. Dahmannm, and Nathan Kettlewell. (2020) "Depression, risk preferences, and risk-taking behavior." Journal of Human Resources, forthcoming.

Cueva, Carlos, R. Edward Roberts, Tom Spencer, Nisha Rani, Michelle Tempest, Philippe N. Tobler, Joe Herbert, and Aldo Rustichini. (2015) "Cortisol and testosterone increase financial risk taking and may destabilize markets." Scientific Reports, 5: 11206.

Dalton, Patricio S., Nguyen Nhung, and Julius Rüschenpöhler. (2020) "Worries of the poor: The impact of financial burden on the risk attitudes of micro-entrepreneurs." Journal of Economic Psychology, 79, 102198.

Daly, Mary C., Daniel J. Wilson, and Norman J. Johnson. (2013) "Relative status and wellbeing: Evidence from U.S. suicide deaths" The Review of Economics and Statistics, 95(5): $1480-1500$.

Dasgupta, Utteeyo, Lata Gangadharan, Pushkar Maitra, and Subha Mani. (2017) "Searching for preference stability in a state dependent world." Journal of Economic Psychology, 2: 17-32.

Dean, Emma Boswell, Frank Schilbach, and Heather Schofield. (2019) "Poverty and cognitive function" in The Economics of Poverty Traps, Eds. C. Barrett, M. Carter, and J.-P. Chavas. University of Chicago Press.

Delaney, Liam, Günther Fink, and Colm Harmon. (2014) "Effects of stress on economic decision-making: Evidence from laboratory experiments." IZA Discussion Paper No. 8060.

Dohmen, Thomas, Armin Falk, David Huffman, and Uwe Sunde. (2010) "Are risk aversion and impatience related to cognitive ability?" American Economic Review, 100(3): 1238-1260.

Dohmen, Thomas, Armin Falk, David Huffman, Uwe Sunde, Jürgen Schupp, and Gert G. Wagner. (2011) "Individual risk attitudes: Measurement, determinants, and behavioral consequences." Journal of the European Economic Association, 9(3): 522-550.

Eibner, Christine, Roland Sturm, and Carole Roan Gresenz. (2004). "Does relative deprivation predict the need for mental health services." Journal of Mental Health Policy and Economics, 7(4): 167-175.

Evans, William N., and Timothy J. Moore. (2011) "The short-term mortality consequences of income receipt." Journal of Public Economics, 95(11): 1410-1424.

Evans, William N., and Timothy J. Moore. (2012) "Liquidity, economic activity, and mortality." Review of Economics and Statistics, 94(2): 400-418.

Falk, Armin, Anke Becker, Thomas Dohmen, Benjamin Enke, David Huffman, and Uwe Sunde. (2018) "Global evidence on economic preferences." The Quarterly Journal of Economics, 133(4): 1645-1692.

Frederick, Shane. (2005) "Cognitive reflection and decision making." Journal of Economic Perspectives, 19(4): 25-42.

Gloede, Oliver, Lukas Menkhoff, and Hermann Waibel. (2015) "Shocks, individual risk attitude, and vulnerability to poverty among rural households in Thailand and Vietnam." World Development, 71: 54-78.

Guiso, Luigi, and Monica Paiella. (2008) "Risk aversion, wealth, and background risk." Journal of the European Economic Association, 6(6): 1109-1150.

Guiso, Luigi, Paola Sapienza, and Luigi Zingales. (2018) “Time varying risk aversion.” Journal of Financial Economics, 128(3): 403-421.

Haisley, Emily, Romel Mostafa, and George Loewenstein. (2008) “Subjective relative income 
and lottery ticket purchases." Journal of Behavioral Decision Making, 21(3): 283-295.

Harrison, Glenn W., Morten I. Lau, and Hong Il Yoo. (2020) "Risk attitudes, sample selection, and attrition in a longitudinal field experiment." The Review of Economics and Statistics, 102(3): 552-568.

Harrison, Glenn W., and Jia Min Ng. (2016) "Evaluating the expected welfare gain from insurance." Journal of Risk and Insurance, 83: 91-120.

Hastings, Justine, and Ebonya Washington. (2010) "The first of the month effect: Consumer behavior and store responses." American Economic Journal: Economic Policy, 2(2): 142162.

Haushofer, Johannes, and Ernst Fehr. (2014) “On the psychology of poverty." Science, 344 (6186): 862-867.

Haushofer, Johannes, and Ernst Fehr. (2019) "Negative income shocks increase discount rates." Unpublished Manuscript.

Huffman, David, and Matias Barenstein. (2005) "A monthly struggle for self-control? Hyperbolic discounting, mental accounting, and the fall in consumption between paydays." Unpublished Manuscript.

Jones, Andrew M., and John Wildman. (2008). "Health, income and relative deprivation: Evidence from the BHPS." Journal of Health Economics, 27(2): 308-324.

Kandasamy, Narayanan, Ben Hardy, Lionel Page, Markus Schaffner, Johann Graggaber, Andrew S. Powlson, Paul C. Fletcher, Mark Gurnell, and John Coates. (2014) "Cortisol shifts financial risk preferences." Proceedings of the National Academy of Sciences, 111(9): 36083613.

Kimball, Miles S, Claudia R Sahm, and Matthew D Shapiro. (2008) "Imputing risk tolerance from survey responses." Journal of the American Statistical Association, 103(483): 10281038.

Kondo, Ayako, and Hitoshi Shigeoka. (2017) "The effectiveness of demand-side government intervention to promote elderly employment: Evidence from Japan." Industrial and Labor Relations Review, 70(4): 1008-1026.

Kremer, Michael, Gautam Rao, and Frank Schilbach. (2019): "Behavioral development economics." in Handbook of Behavioral Economics, vol. 2, ed. by D. Bernheim, S. DellaVigna, and D. Laibson. Elsevier.

Krupka, Erin L., and Melvin Stephens. (2013) "The stability of measured time preferences." Journal of Economic Behavior and Organization, 85: 11-19.

Lawrance, Emily C. (1991) "Poverty and the rate of time preference: Evidence from panel data." Journal of Political Economy, 99(1): 54-77.

Lerner, Jennifer S., Ye Li, Piercarlo Valdesolo, and Karim S.Kassam. (2015) "Emotion and decision making." Annual Review of Psychology, 66: 799-823.

Lichand, Guilherme, and Anandi Mani. (2019) "Cognitive droughts." Unpublished Manuscript.

Mani, Anandi, Sendhil Mullainathan, Eldar Shafir, and Jiaying Zhao. (2013) "Poverty impedes cognitive function." Science, 341(6149): 976-980.

Mani, Anandi, Sendhil Mullainathan, Eldar Shafir, and Jiaying Zhao. (2020) "Scarcity and cognitive function around payday: A conceptual and empirical analysis." Journal of the Association for Consumer Research, 5(4): 365-376.

Mastrobuoni, Giovanni, and Matthew Weinberg. (2009) "Heterogeneity in intra-monthly consumption patterns, self-control, and savings at retirement." American Economic Journal: Economic Policy, 1(2): 163-189. 
Mastrobuoni, Giovanni, and Matthew Weinberg. (2010) "Do Social Security recipients smooth consumption between checks? Evidence using new data with variation in pay dates." Unpublished Manuscript.

Mata, Rui, Renato Frey, David Richter, Jürgen Schupp, and Ralph Hertwig. (2018) "Risk preference: A view from psychology." Journal of Economic Perspectives, 32(2): 155-172.

Mather, Mara, Marissa A. Gorlick, and Nichole R. Lighthall. (2009) "To brake or accelerate when the light turns yellow? Stress reduces older adults' risk taking in a driving game." Psychological Science, 20(2): 174-176.

Meier, Stephan, and Charles D. Sprenger. (2015) "Temporal stability of time preferences." The Review of Economics and Statistics, 97(2): 273-286.

Mishra, Sandeep. (2014) "Decision-making under risk: Integrating perspectives from biology, economics, and psychology." Personality and Social Psychology Review, 18(3): 280-307.

Mishra, Sandeep, and Martin L. Lalumière. (2010) "You can't always get what you want: The motivational effect of need on risk-sensitive decision-making." Journal of Experimental Social Psychology, 46(4): 605-611.

Mishra, Sandeep, Leanne S. Son Hing, and Martin L. Lalumière. (2015) "Inequality and risktaking." Evolutionary Psychology, 13: 1-11.

Mullainathan, Sendhil, and Eldar Shafir. (2013) Scarcity: Why Having Too Little Means So Much. New York: Times Books.

Necker Sarah, and Michael Ziegelmeyer. (2016) "Household risk taking after the financial crisis." The Quarterly Review of Economics and Finance, 59: 141-160.

Pabst, Stephan, Matthias Brand, and Oliver T. Wolf. (2013a) "Stress and decision making: A few minutes make all the difference." Behavioural Brain Research, 250: 39-45.

Pabst, Stephan, Daniela Schoofs, Mirko Pawlikowski, Matthias Brand, and Oliver T. Wolf. (2013b). "Paradoxical effects of stress and an executive task on decisions under risk." Behavioral Neuroscience, 127(3): 369-379.

Payne, B. Keith, Jazmin L. Brown-Iannuzzi, and Jason W. Hannay. (2017) "Economic inequality increases risk taking." Proceedings of the National Academy of Sciences, 114(18): 46434648.

Pietras, Cynthia J., and Timothy D. Hackenberg. (2001) "Risk-sensitive choice in humans as a function of an earnings budget." Journal of the Experimental Analysis of Behavior, 76:1-19.

Porcelli, Anthony J, and Mauricio R Delgado. (2009). "Acute stress modulates risk taking in financial decision making." Psychological Science, 20(3): 278-283.

Pratt, John W. (1964) "Risk Aversion in the small and in the large." Econometrica, 32(1/2): 122136.

Putman, Peter, Niki Antypa, Panagiota Crysovergi, and Willem A. J. van der Does. (2010) "Exogenous cortisol acutely influences motivated decision making in healthy young men." Psychopharmacology, 208: 257-263.

Rabin, Matthew. (2000) "Risk aversion and expected-utility theory: a calibration theorem." Econometrica, 68(5): 1281-1292.

Rekaiti, Pamaria, and Roger Van den Bergh. (2000) "Cooling-off periods in the consumer laws of the EC member states: A comparative Law and Economics approach." Journal of Consumer Policy, 23: 371-407.

Ridley, Matthew W., Gautam Rao, Frank Schilbach, and Vikram H. Patel. (2020) "Poverty, depression, and anxiety: Causal evidence and mechanisms." NBER Working Paper No. 27157. 
Sahm, Claudia R. (2012) “How much does risk tolerance change?” Quarterly Journal of Finance, 2(4): Article 5.

Schilbach, Frank, Heather Schofield, and Sendhil Mullainathan. (2016) "The psychological lives of the poor." American Economic Review: Papers \& Proceedings, 106(5): 435-440.

Schildberg-Hörisch, Hannah. (2018) “Are risk preferences stable?” Journal of Economic Perspectives, 32(2): 135-154.

Shah, Anuj K., Sendhil Mullainathan, and Eldar Shafir. (2012). "Some consequences of having too little." Science, 338(6107): 682-685.

Shapiro, Jesse M. (2005) "Is there a daily discount rate? Evidence from the food stamp nutrition cycle." Journal of Public Economics, 89(2-3): 303-325.

Social Security Administration. (2019) "Social security administration beneficiaries trend in direct deposit participation percent direct deposit September 2019." (accessed 10/03/2020 https://www.ssa.gov/deposit/GIS/data/Reports/DDTREND2.htm)

Sokol-Hessner, Peter, Candace M. Raio, Sarah P. Gottesman, Sandra F. Lackovic, and Elizabeth A. Phelps. (2016) "Acute stress does not affect risky monetary decision-making." Neurobiology of Stress, 5: 19-25.

Spears, Dean. (2011) "Economic decision-making in poverty depletes behavioral control." B.E. Journal of Economic Analysis \& Policy, 11(1): 1-44.

Starcke, Katrin, Oliver T. Wolf, Hans J. Markowitsch, and Matthias Brand (2008). "Anticipatory stress influences decision making under explicit risk conditions." Behavioral Neuroscience, 122(6): 1352-1360.

Stephens Jr., Melvin. (2003) “'3rd of the Month': Do Social Security recipients smooth consumption between checks?" American Economic Review, 93(1): 406-422.

Stephens Jr., Melvin. (2006) "Paycheck receipt and the timing of consumption." The Economic Journal, 116(513): 680-701.

Stephens Jr., Melvin., and Takashi Unayama. (2011) "The consumption response to seasonal income: Evidence from Japanese public pension benefits." American Economic Journal: Applied Economics, 3(4): 86-118.

Stigler, George J., and Gary S. Becker. (1977) "De gustibus non est disputandum.” American Economic Review, 67(2): 76-90.

Tanaka, Tomomi, Colin Camerer, and Quang Nguyen. (2010) "Risk and time preferences: linking experimental and household survey data from Vietnam." American Economic Review, 100(1): 557-571.

Vellekoop, Nathanael. (2018) "Explaining intra-monthly consumption patterns: The timing of income or the timing of consumption commitments?" Unpublished Manuscript.

Volk, Stefan, Christian Thöni, and Winfried Ruigrok. (2012) "Temporal stability and psychological foundations of cooperation preferences." Journal of Economic Behavior and Organization, 81: 664-676.

Wilde, Parke E., and Christine K. Ranney. (2000) "The monthly food stamp cycle: Shopping frequency and food intake decisions in an endogenous switching regression framework." American Journal of Agricultural Economics, 82(1): 200-213.

WHO. (2017) "Mental health of older adults." (accessed 10/05/2020 https://www.who.int/newsroom/fact-sheets/detail/mental-health-of-older-adults) 


\section{Figure 1-Conceptual framework of time-varying risk preferences}

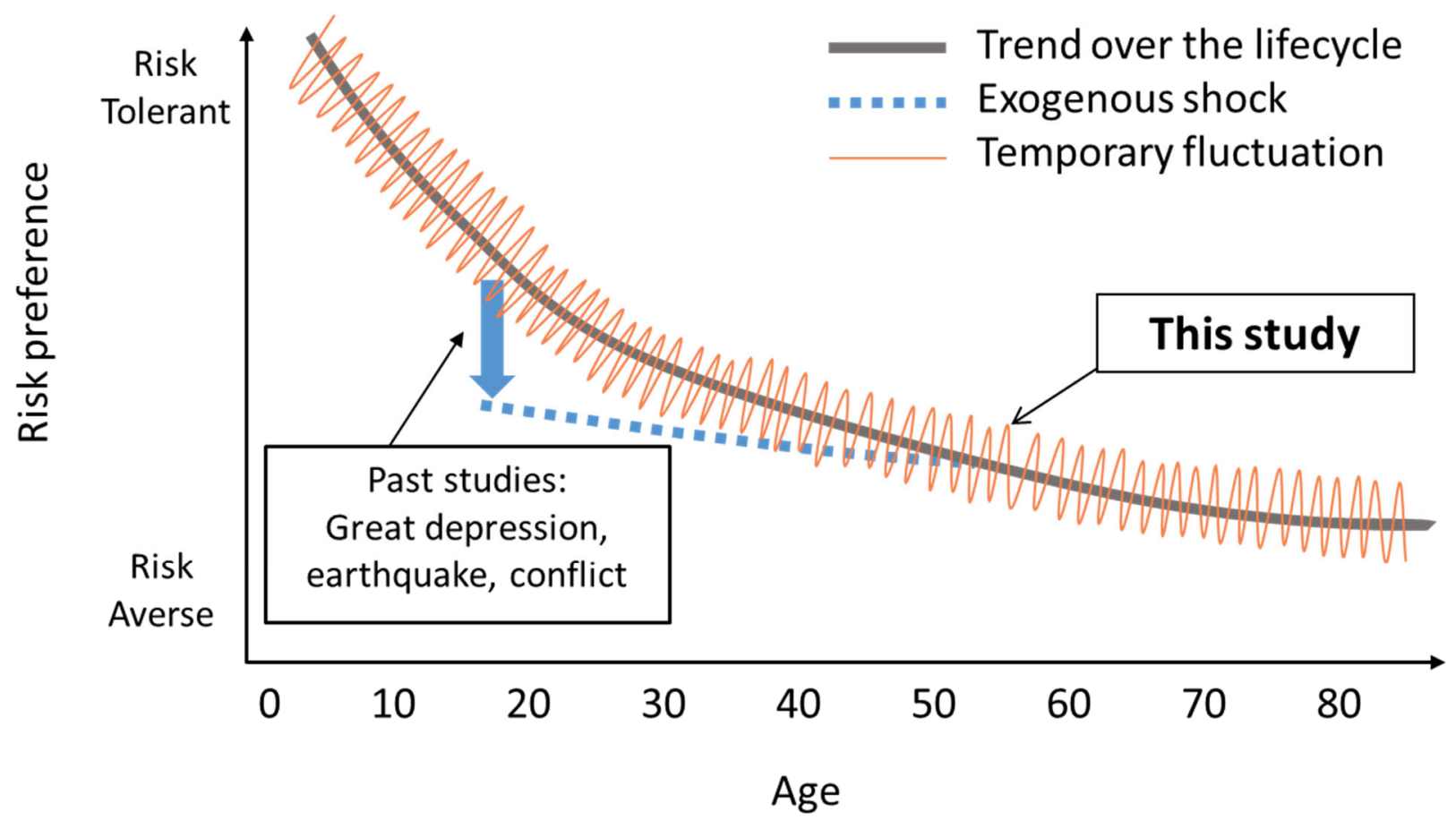

Source: This figure is adapted from Schildberg-Hörisch (2018, Figure 1). The figure provides the conceptual framework of time-varying risk preference throughout the life course. The $x$-axis is the age and the $y$-axis is the risk preference where the higher value indicates more risk tolerance. The solid line shows increasing baseline risk aversion based on the empirical evidence that people become more risk averse as they get older. The dashed line shows a possible permanent shift from baseline risk preference due to a large, one-time, permanent, and unanticipated shock such as the Great Depression. The jagged line represents a temporal shift around baseline risk preference due to periodic payments as we investigate in this study. 
Figure 2-Risk tolerance before and after payday

(a) SS/income share above 50 percent

$(\mathrm{N}=527)$

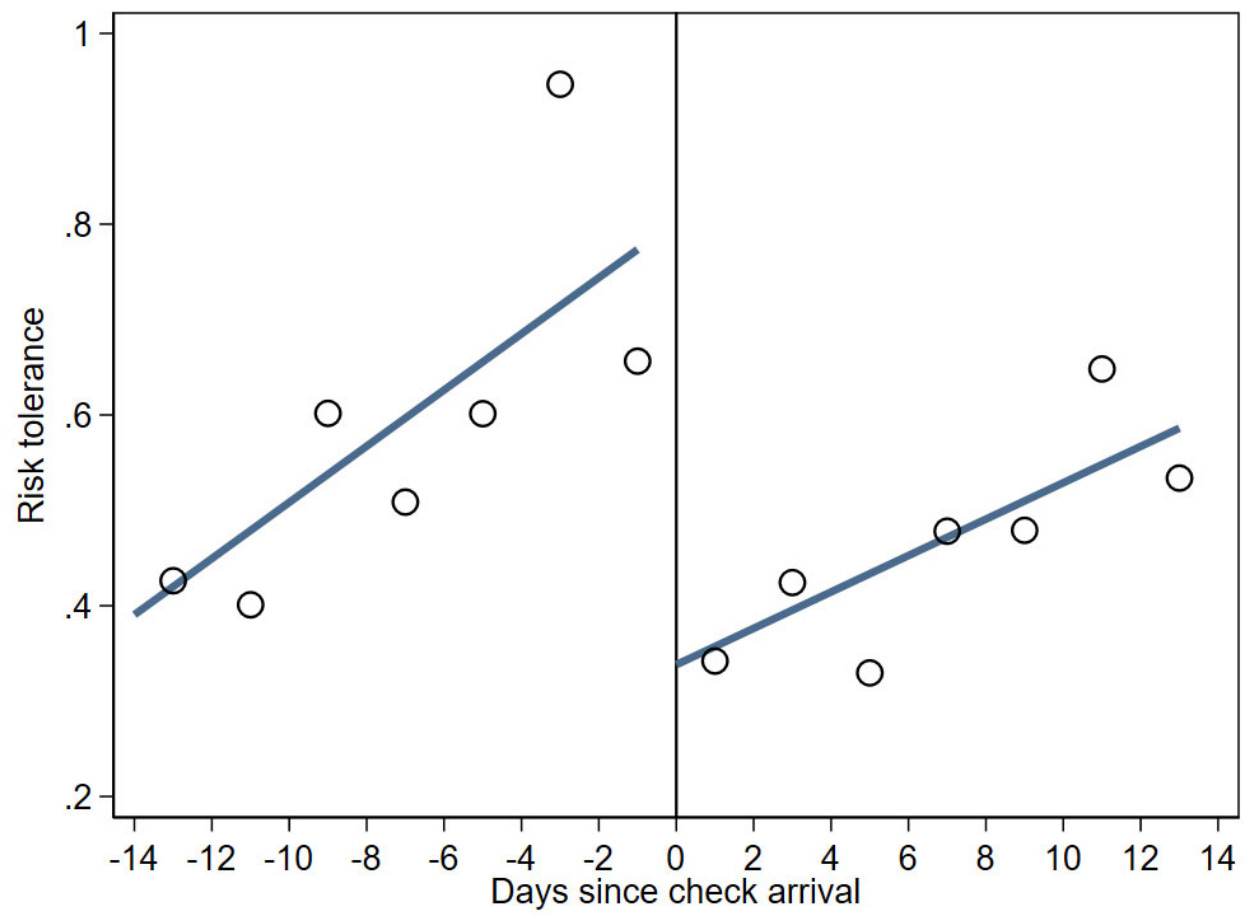

(b) SS/income share below 50 percent

$(\mathrm{N}=700)$

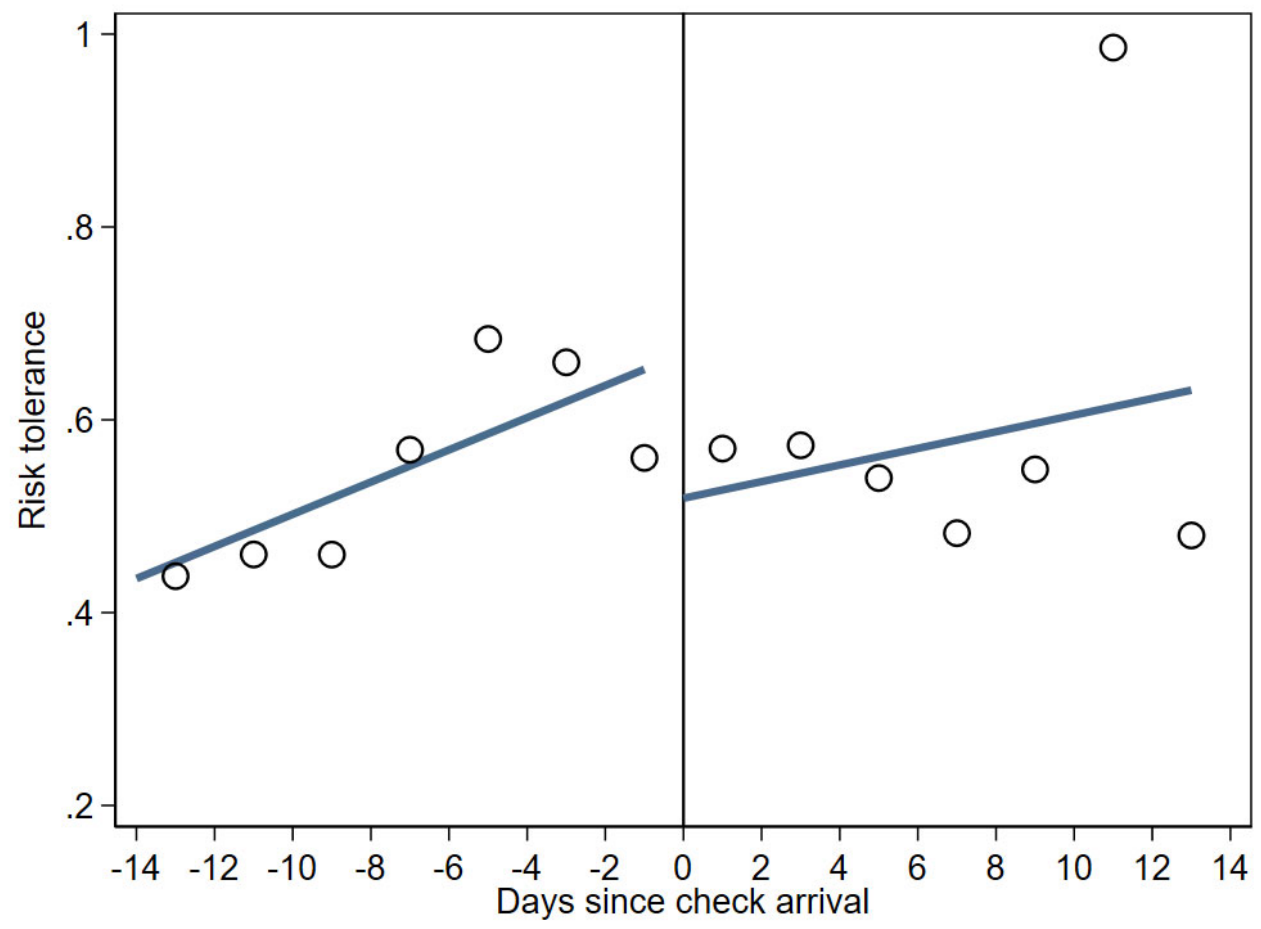

Notes: The data come from the Health and Retirement Study (HRS) in 1994, 1998, 2000, 2002, and 2006. The sample is individuals whose share of Social Security (SS) among total household income is above 50\% in panel (a) and below 50\% in panel (b). Each plot represents the two-day average of risk tolerance for two weeks before and after payday. The line corresponds to the linear fit. See the main text for the construction of risk tolerance measures. 
Table 1-Descriptive statistics

\begin{tabular}{lrrrrr}
\hline \hline Variables & \multicolumn{1}{c}{ Obs } & \multicolumn{1}{c}{ Mean } & \multicolumn{1}{c}{ SD } & Min & Max \\
\hline Risk tolerance: $\theta$ & 1227 & 0.540 & 0.834 & 0.13 & 3.27 \\
Days since check arrival & 1227 & 0.482 & 8.59 & -14 & 13 \\
Social security benefits/household income & 1227 & 0.481 & 0.279 & 0 & 1 \\
Non-savers & 1227 & 0.346 & 0.476 & 0 & 1 \\
Cognition & & & & & \\
$\quad$ Normal & 1185 & 0.831 & 0.374 & 0 & 1 \\
CIND & 1185 & 0.149 & 0.356 & 0 & 1 \\
Dementia & 1185 & 0.019 & 0.138 & 0 & 1 \\
Depression & 1226 & 0.115 & 0.319 & 0 & 1 \\
Individual characteristics: & & & & & \\
Age (in years) & 1227 & 69.251 & 3.355 & 62 & 85 \\
Female & 1227 & 0.504 & 0.500 & 0 & 1 \\
Years of schooling & 1227 & 12.383 & 2.950 & 0 & 17 \\
Married & 1227 & 0.924 & 0.264 & 0 & 1 \\
Retired & 1227 & 0.756 & 0.429 & 0 & 1 \\
Household size & 1227 & 1.944 & 0.228 & 1 & 2 \\
Northeast & 1227 & 0.174 & 0.379 & 0 & 1 \\
Midwest & 1227 & 0.292 & 0.455 & 0 & 1 \\
South & 1227 & 0.349 & 0.477 & 0 & 1 \\
West & 1227 & 0.183 & 0.387 & 0 & 1 \\
Good health & 1227 & 0.439 & 0.496 & 0 & 1 \\
Poor health & 1227 & 0.245 & 0.430 & 0 & 1 \\
African American & 1227 & 0.069 & 0.254 & 0 & 1 \\
\hline Noen & &
\end{tabular}

Notes: The data come from the Health and Retirement Study (HRS) in 1994, 1998, 2000, 2002, and 2006. Non-savers are defined as individuals whose overall savings have a net value under $\$ 10,000$. The measures of cognition are classified as normal, cognitive impairment, not dementia (CIND), and dementia, which are mutually exclusive. See section 4.3 for the definition of each cognition variable. Depression is a dummy that takes the value of one if the person felt depressed much of the time during the past week. 
Table 2-Test for randomization of interview dates

\begin{tabular}{|c|c|c|c|c|c|c|c|c|c|c|c|c|c|}
\hline & Age & Female & $\begin{array}{c}\text { Yrs. of } \\
\text { schooli } \\
\text { ng }\end{array}$ & Married & Retired & $\begin{array}{l}\text { Househ } \\
\text { old size }\end{array}$ & $\begin{array}{c}\text { Northea } \\
\text { st }\end{array}$ & $\begin{array}{c}\text { Midwes } \\
\mathrm{t}\end{array}$ & South & West & $\begin{array}{l}\text { Good } \\
\text { health }\end{array}$ & $\begin{array}{c}\text { Poor } \\
\text { health }\end{array}$ & $\begin{array}{c}\text { African } \\
\text { Americ } \\
\text { an }\end{array}$ \\
\hline \multicolumn{14}{|c|}{ (a) Full sample } \\
\hline F-stat & 0.642 & 0.216 & 0.536 & 0.572 & 0.462 & 1.608 & 3.316 & 0.569 & 4.146 & 5.765 & 0.646 & 0.887 & 1.846 \\
\hline p-value & 0.587 & 0.885 & 0.657 & 0.633 & 0.708 & 0.185 & 0.019 & 0.634 & 0.006 & 0.0006 & 0.585 & 0.446 & 0.136 \\
\hline $\mathrm{N}$ & 1227 & 1227 & 1227 & 1227 & 1227 & 1227 & 1227 & 1227 & 1227 & 1227 & 1227 & 1227 & 1227 \\
\hline \multicolumn{14}{|c|}{ (b) SS/income share above 50 percent } \\
\hline F-stat & 0.608 & 0.145 & 0.617 & 0.658 & 0.233 & 1.484 & 3.421 & 0.323 & 2.974 & 1.347 & 1.049 & 1.627 & 1.054 \\
\hline p-value & 0.609 & 0.932 & 0.603 & 0.578 & 0.873 & 0.217 & 0.017 & 0.808 & 0.031 & 0.258 & 0.370 & 0.182 & 0.367 \\
\hline $\mathrm{N}$ & 527 & 527 & 527 & 527 & 527 & 527 & 527 & 527 & 527 & 527 & 527 & 527 & 527 \\
\hline \multicolumn{14}{|c|}{ (c) SS/income share below 50 percent } \\
\hline F-stat & 0.593 & 0.384 & 1.503 & 0.351 & 1.227 & 0.371 & 2.048 & 1.047 & 2.203 & 4.745 & 2.782 & 1.565 & 2.176 \\
\hline p-value & 0.619 & 0.763 & 0.212 & 0.787 & 0.298 & 0.773 & 0.105 & 0.370 & 0.086 & 0.002 & 0.040 & 0.194 & 0.089 \\
\hline $\mathrm{N}$ & 700 & 700 & 700 & 700 & 700 & 700 & 700 & 700 & 700 & 700 & 700 & 700 & 700 \\
\hline
\end{tabular}

Notes: The data come from the Health and Retirement Study (HRS) in 1994, 1998, 2000, 2002, and 2006. F-stats and p-values correspond to joint null tests whereby each of the coefficients on the four-week dummies is zero. The sample is individuals whose share of Social Security (SS) among total household income is above 50\% in panel (b) and below 50\% in panel (c). 
Table 3-Main results: Risk tolerance

\begin{tabular}{lcc}
\hline \hline & \multicolumn{2}{c}{ SS/income share } \\
\cline { 2 - 3 } & above 50 percent & below 50 percent \\
& $(1)$ & $(2)$ \\
\hline Week -2 & 0.040 & -0.025 \\
Week -1 & $(0.094)$ & $(0.096)$ \\
& $0.352^{* *}$ & 0.068 \\
Week +2 & $(0.139)$ & $(0.109)$ \\
& 0.154 & 0.103 \\
Covariates & $(0.098)$ & $(0.087)$ \\
Mean of outcome & $\times$ & $\times$ \\
N & 0.514 & 0.559 \\
R squared & 527 & 700 \\
\hline
\end{tabular}

Notes: The data come from the Health and Retirement Study (HRS) in 1994, 1998, 2000, 2002, and 2006. The sample is individuals whose share of Social Security (SS) among total household income is above 50\% in panel (a) and below 50\% in panel (b). The outcome is risk tolerance. estimates $\beta_{k}(k=-2,-1,+2)$ from equation [1] are reported with robust errors in parentheses. The omitted category is week +1 . Covariates include age, age squared, gender, household size, self-reported health indicators, highest years of schooling, marital status, race, retirement status, MSA status dummies, calendar week fixed effects (FEs), year FEs, month FEs, and year-month FEs. See the main text for the construction of each preference measure. Significance levels: ${ }^{* * *} \mathrm{p}<0.01,{ }^{* *} \mathrm{p}<0.05,{ }^{*} \mathrm{p}<0.10$

Table 4-Different thresholds: Risk tolerance

\begin{tabular}{lccc}
\hline \hline & \multicolumn{3}{c}{ SS/income share } \\
\cline { 2 - 4 } & above 50 percent & above 40 percent & above 60 percent \\
& $(1)$ & $(2)$ & $(3)$ \\
\hline Week -2 & 0.040 & 0.013 & 0.052 \\
& $(0.094)$ & $(0.080)$ & $(0.123)$ \\
Week -1 & $0.352^{* *}$ & $0.264^{* *}$ & $0.320^{*}$ \\
& $(0.139)$ & $(0.118)$ & $(0.165)$ \\
Week +2 & 0.154 & 0.122 & 0.042 \\
& $(0.098)$ & $(0.085)$ & $(0.111)$ \\
\hline Covariates & $\times$ & $\times$ & 0.494 \\
Mean of outcome & 0.514 & 0.511 & 380 \\
N & 527 & 681 & 0.168 \\
R squared & 0.134 & 0.125 & 31 percent \\
Sample share & 43 percent & 56 percent & $\times 11$ \\
\hline
\end{tabular}

Notes: The data come from the Health and Retirement Study (HRS) in 1994, 1998, 2000, 2002, and 2006. Column (1) replicates the baseline results of column (1) in Table 3. The sample is limited to SS/income share above $40 \%$ in columns (2), and above $60 \%$ in column (3). The outcome is risk tolerance. The estimates $\beta_{k}(k=-2,-1,+2)$ from equation [1] are reported with robust errors in parentheses. The omitted category is week +1 . Covariates include age, age squared, gender, household size, self-reported health indicators, highest years of schooling, marital status, race, retirement status, MSA status dummies, calendar week fixed effects (FEs), year FEs, month FEs, and year-month FEs. SS stands for Social Security. Significance levels: ${ }^{* * *} \mathrm{p}<0.01,{ }^{* *} \mathrm{p}<0.05,{ }^{*} \mathrm{p}<0.10$ 
Table 5-Other robustness checks: Risk tolerance

\begin{tabular}{lccc}
\hline \hline & $\begin{array}{c}\text { Risk tolerance } \\
\text { categories } \\
5 \text { or } 6\end{array}$ & $\begin{array}{c}\text { Ordered } \\
\text { Probit }\end{array}$ & $\begin{array}{c}\text { Interval } \\
\text { regression }\end{array}$ \\
\hline Week -2 & $(1)$ & $(2)$ & $(3)$ \\
Week -1 & $(0.014$ & 0.026 & 0.057 \\
& $0.118^{* *}$ & $(0.149)$ & $(0.208)$ \\
Week +2 & $(0.055)$ & $0.399 * *$ & $0.630^{* *}$ \\
& 0.041 & $(0.188)$ & $(0.280)$ \\
Covariates & $(0.039)$ & 0.165 & 0.272 \\
Mean of outcome & $\times$ & $(0.147)$ & $(0.209)$ \\
$\mathrm{N}$ & 0.113 & $\times$ & $\times$ \\
\hline
\end{tabular}

Notes: The data come from the Health and Retirement Study (HRS) in 1994, 1998, 2000, 2002, and 2006. The sample is limited to individuals whose share of Social Security (SS) among total household income is above $50 \%$. The estimates $\beta_{k}(k=-2,-1,+2)$ from equation [1] are reported with robust errors in parentheses. The omitted category is week +1 . The outcome in column (1) is a binary measure of risk preference that takes the value of 1 if the person chose the highest or second-highest risk tolerance categories (categories 5 or 6) and 0 otherwise. The outcome in column (2) is an ordinal measure of risk preference coded from 1 for the lowest risk tolerance category to 6 for the highest category. Column (3) reports the estimates of the interval regression. Covariates include age, age squared, gender, household size, self-reported health indicators, highest years of schooling, marital status, race, retirement status, MSA status dummies, calendar week fixed effects (FEs), year FEs, month FEs, and year-month FEs. Significance levels: ${ }^{* * *} \mathrm{p}<0.01,{ }^{* *} \mathrm{p}<0.05,{ }^{*}$ $\mathrm{p}<0.10$

Table 6-Cognition

\begin{tabular}{lccc}
\hline \hline \multicolumn{1}{c}{ Outcome: } & Normal & CIND & Dementia \\
& $(1)$ & $(2)$ & $(3)$ \\
\hline Week -2 & 0.073 & -0.062 & -0.011 \\
& $(0.052)$ & $(0.053)$ & $(0.022)$ \\
Week -1 & 0.089 & -0.065 & -0.025 \\
& $(0.063)$ & $(0.063)$ & $(0.026)$ \\
Week +2 & 0.071 & -0.037 & -0.034 \\
& $(0.051)$ & $(0.052)$ & $(0.024)$ \\
\hline Covariates & $\times$ & $\times$ & $\times$ \\
Mean of outcome & 0.756 & 0.208 & 0.034 \\
N & 518 & 518 & 518 \\
R squared & 0.278 & 0.207 & 0.308 \\
\hline
\end{tabular}

Notes: The data come from the Health and Retirement Study (HRS) in 1994, 1998, 2000, 2002, and 2006. The sample is limited to individuals whose share of Social Security (SS) among total household income is above 50\%. The classification is based on a 27-point score composed of the word recall, serial sevens, and backward counting tests. Scores between 12 and 27 are classified as normal, between 7 and 11 as cognitive impairment, not dementia (CIND), and between 0 and 6 as dementia. The estimates $\beta_{k}(k=-2,-1,+2)$ from equation [1] are reported with robust errors in parentheses. The omitted category is week +1 . Covariates include age, age squared, gender, household size, self-reported health indicators, highest years of schooling, marital status, race, retirement status, MSA status dummies, calendar week fixed effects (FEs), year FEs, month FEs, and year-month FEs. Significance levels: ${ }^{* * *} \mathrm{p}<0.01,{ }^{* *} \mathrm{p}<0.05$, $\mathrm{p}<0.10$ 
Table 7-Depression

\begin{tabular}{lcccccc}
\hline \hline & \multicolumn{7}{c}{ SS/income share } & & \\
\cline { 2 - 7 } & \multicolumn{2}{c}{ above 50 percent } & \multicolumn{2}{c}{ above 40 percent } & \multicolumn{2}{c}{ above 60 percent } \\
\cline { 2 - 7 } & OLS & Probit & OLS & Probit & OLS & Probit \\
& $(1)$ & $(2)$ & $(3)$ & $(4)$ & $(5)$ & $(6)$ \\
\hline Week -2 & 0.024 & 0.023 & 0.024 & 0.018 & 0.051 & 0.057 \\
Week -1 & $(0.054)$ & $(0.047)$ & $(0.048)$ & $(0.041)$ & $(0.069)$ & $(0.058)$ \\
& $0.081^{*}$ & $0.076^{*}$ & 0.062 & $0.056^{*}$ & $0.118^{* *}$ & $0.127^{* *}$ \\
Week +2 & $(0.046)$ & $(0.040)$ & $(0.038)$ & $(0.033)$ & $(0.059)$ & $(0.049)$ \\
& 0.009 & -0.002 & -0.031 & -0.049 & 0.039 & 0.035 \\
Covariates & $(0.038)$ & $(0.041)$ & $(0.031)$ & $(0.034)$ & $(0.051)$ & $(0.056)$ \\
Mean of outcome & 0.153 & 0.163 & 0.143 & 0.148 & 0.176 & 0.180 \\
N & 527 & 478 & 681 & 638 & 380 & 343 \\
Sample share & $43 \%$ & $39 \%$ & $56 \%$ & $52 \%$ & $31 \%$ & $28 \%$ \\
\hline
\end{tabular}

Notes: The data come from the Health and Retirement Study (HRS) in 1994, 1998, 2000, 2002, and 2006. The sample is limited to SS/income share above 50\% in columns (1) and (2), above $40 \%$ in columns (3) and (4), and above $60 \%$ in columns (5) and (6). The outcome is a dummy that takes the value of one if the person felt depressed much of the time during the past week. The estimates $\beta_{k}(k=-2,-1,+2)$ from equation [1] are reported with robust errors in parentheses. The omitted category is week +1 . Note that since the reference period of this question is a week from the survey date, we define the week dummies in equation [1] accordingly. Covariates include age, age squared, gender, household size, self-reported health indicators, highest years of schooling, marital status, race, retirement status, MSA status dummies, calendar week fixed effects (FEs), year FEs, month FEs, and year-month FEs. Significance levels: ${ }^{* * *} \mathrm{p}<0.01,{ }^{* *} \mathrm{p}<0.05,{ }^{*} \mathrm{p}<0.10$ 


\section{Table 8-Supplemental analysis from Japan on risk tolerance (JSTAR)}

\begin{tabular}{lcc}
\hline \hline & $(1)$ & $(2)$ \\
\hline Week -4 & -0.017 & -0.020 \\
Week -3 & $(0.032)$ & $(0.032)$ \\
& -0.028 & -0.026 \\
Week -2 & $(0.039)$ & $(0.039)$ \\
& 0.027 & 0.030 \\
Week -1 & $(0.030)$ & $(0.030)$ \\
& $0.056^{* *}$ & $0.059 * *$ \\
& $(0.027)$ & $(0.027)$ \\
Week +2 & & \\
& 0.013 & 0.009 \\
Week +3 & $(0.024)$ & $(0.024)$ \\
& -0.005 & -0.004 \\
Week +4 & $(0.029)$ & $(0.029)$ \\
& 0.022 & 0.026 \\
Covariates & $(0.034)$ & $(0.034)$ \\
Mean of outcome & & $\times$ \\
N & 0.153 & 0.153 \\
R squared & 2728 & 2728 \\
N & 0.036 & 0.054 \\
\hline
\end{tabular}

Notes: The data come from the Japanese Study of Aging and Retirement (JSTAR) in 2007, 2009, 2011, and 2013 (N = 2728 ). The outcome is risk tolerance. The estimates $\beta_{k}(k=-4,-3,-2,-1,+2,+3,+4)$ from equation [1]' are reported with robust errors in parentheses. The omitted category is week +1 . Covariates include age, age squared, and dummy variables for gender, marital status, educational background, sampling cohort, working status, and good and bad health status. Time effects are related to the date of the survey interview and include dummy variables for the year, month, interactions of year and month, day of the week, number of weeks, and interactions of the day of week and number of weeks of the interview date. See the main text for the construction of risk preference measures. Significance levels: ${ }^{* * *} \mathrm{p}<0.01,{ }^{* *} \mathrm{p}<0.05,{ }^{*} \mathrm{p}<0.10$ 


\section{Table 9-Supplemental analysis from Japan on potential mechanisms (JGSS)}

\begin{tabular}{lccccc}
\hline \hline Outcomes: & \multicolumn{2}{c}{ Feel financially anxious } & & \multicolumn{2}{c}{ Low self-perceived social status } \\
\cline { 2 - 3 } \cline { 5 - 6 } & OLS & Probit & & OLS & Probit \\
& $(1)$ & $(2)$ & & $(3)$ & $(4)$ \\
\hline Week -2 & $0.150^{*}$ & $0.169^{* *}$ & & 0.008 & 0.006 \\
& $(0.091)$ & $(0.080)$ & & $(0.039)$ & $(0.043)$ \\
Week -1 & $0.206^{* *}$ & $0.222^{* * *}$ & & $0.076^{* *}$ & $0.076^{* *}$ \\
& $(0.092)$ & $(0.078)$ & & $(0.038)$ & $(0.038)$ \\
Week +2 & 0.098 & 0.110 & & 0.023 & 0.026 \\
& $(0.099)$ & $(0.088)$ & & $(0.037)$ & $0.043)$ \\
\hline Covariates & $\times$ & $\times$ & & $\times$ & $\times$ \\
Mean of outcome & 0.628 & 0.649 & & 0.099 & 0.117 \\
N & 277 & 262 & & 593 & 503 \\
R squared & 0.296 & - & & 0.101 & - \\
\hline
\end{tabular}

Notes: The data come from the Japanese General Social Surveys (JGSS) in 2008. The estimates $\beta_{k}(k=-2,-1,+2)$ from estimating an equation [1] are reported with robust errors in parentheses. The omitted category is week +1 . The outcome in columns (1) and (2) is a dummy that takes the value of one if the respondents choose either "I feel very anxious" or "I feel somewhat anxious" to the question "Do you feel anxious about your economic situation in the future?" or zero otherwise. The outcome in columns (3) and (4) is a dummy that takes the value of one if the respondents choose the lowest and second-lowest categories (categories 9 and 10) to the question "If we were to divide the contemporary Japanese society into the following ten strata, which would you say you belong to?" or zero otherwise. Covariates include dummy variables for age, gender, marital status, educational background, working status, good and bad health status, region fixed effects (FEs), and month FEs. Significance levels: ${ }^{* * *} \mathrm{p}<0.01,{ }^{* *} \mathrm{p}<0.05,{ }^{*} \mathrm{p}<0.10$ 


\section{Online Appendix (Not for Publication)}




\section{Appendix A: Analysis for the US (HRS)}

Figure A1-The relationship between the share of Social Security income out of total household income and total household income

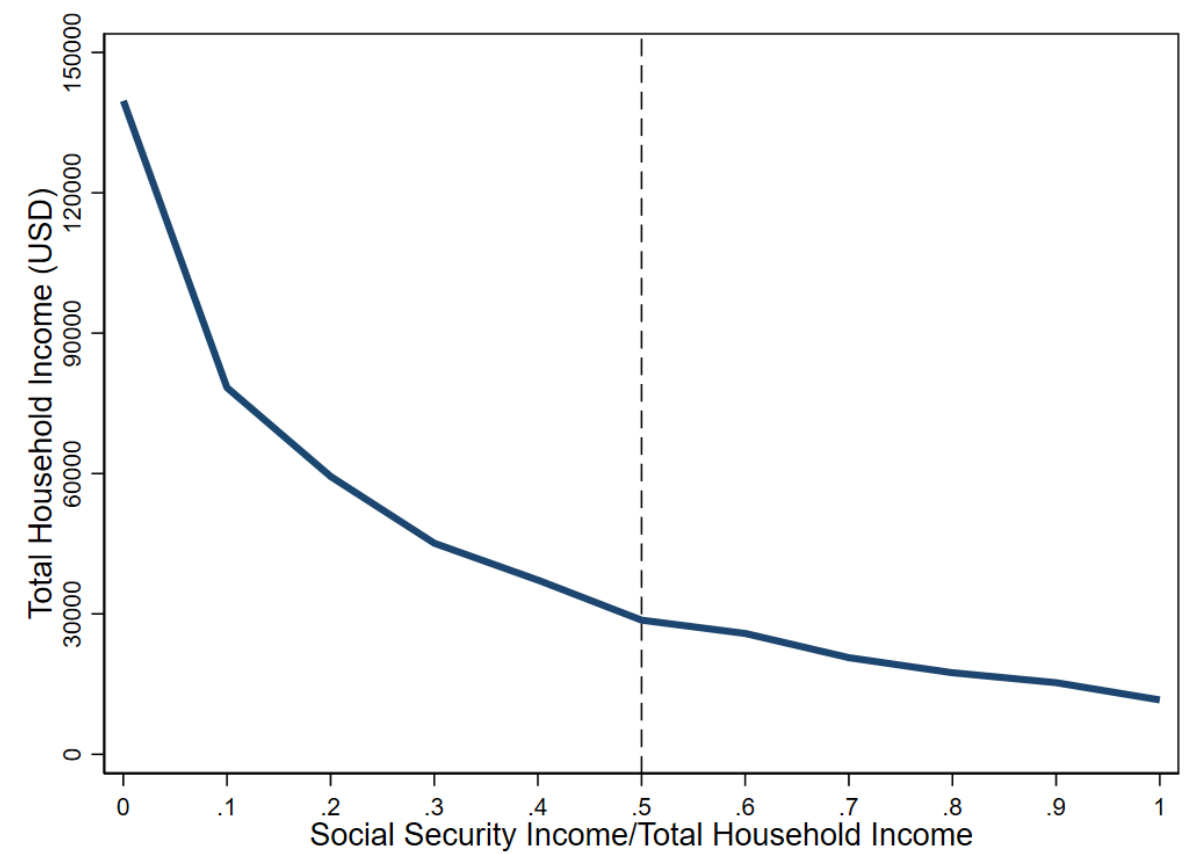

Notes: The data come from the Health and Retirement Study (HRS) in 1994, 1998, 2000, 2002, and 2006. The $x$-axis is the share of Social Security income out of total household income, and the $y$-axis is the total household income. The dotted line corresponds to an income share of at least $50 \%$ or 0.5 (which comprises $43 \%$ of the full sample). 


\section{Figure A2-Frequency distributions}

(a) Risk preferences ( $\mathrm{N}=1227)$

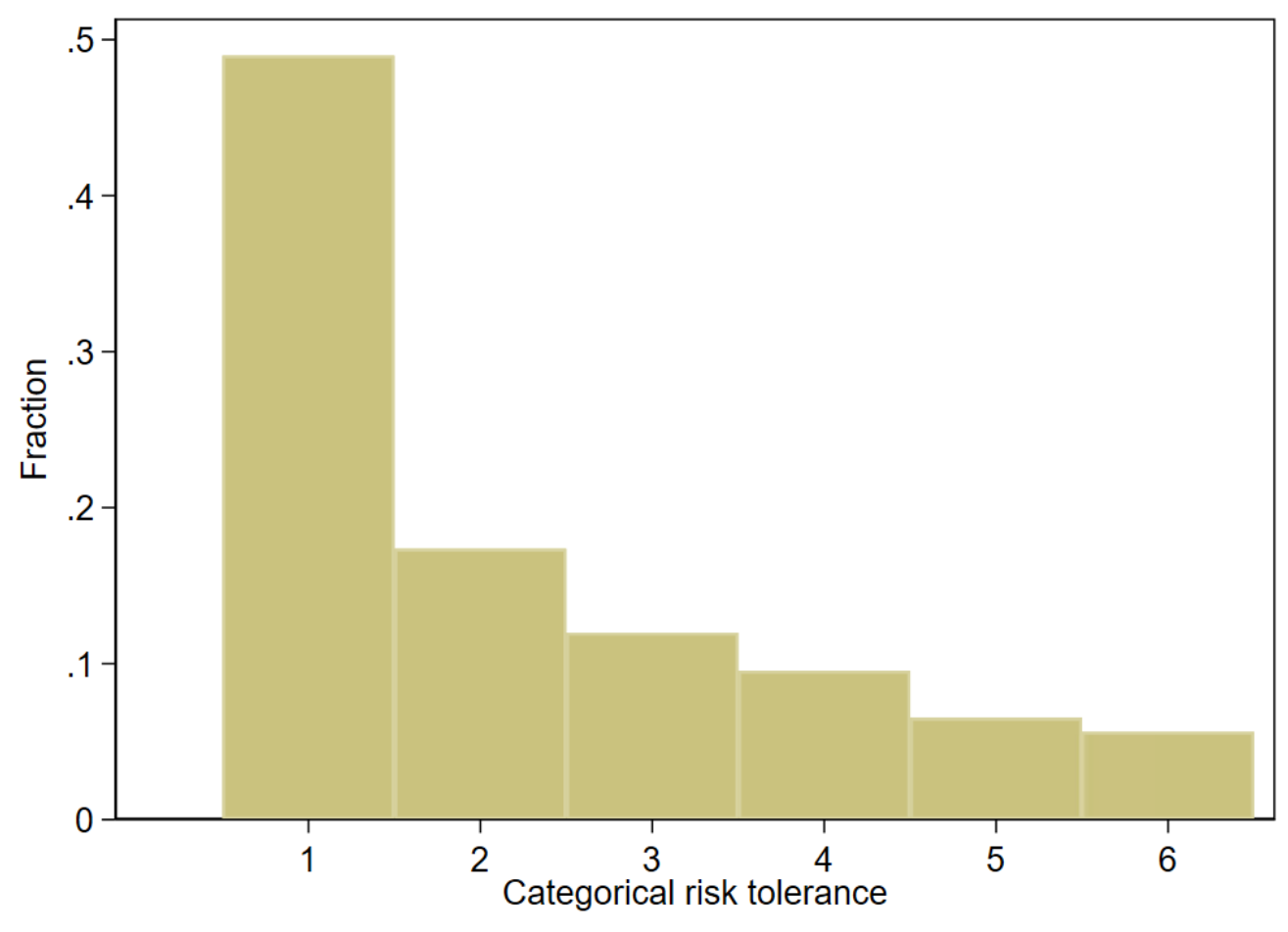

(b) Cognition $(\mathrm{N}=1185)$

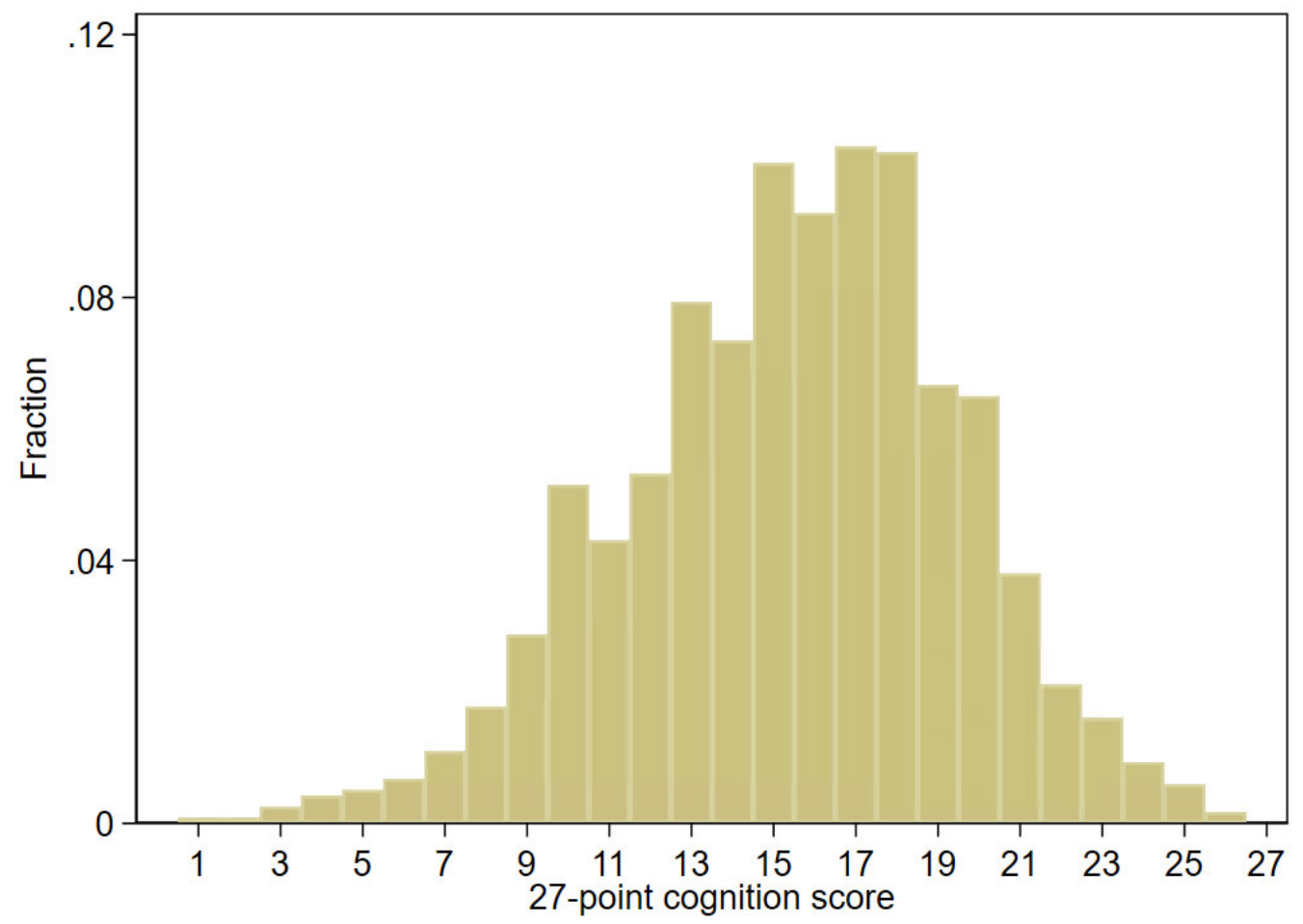

Notes: The data come from the Health and Retirement Study (HRS) in 1994, 1998, 2000, 2002, and 2006. Table A1 provides the relationship between the gamble response category and the downside risks that the individual accepts or rejects. See Appendix Table D1 for the questionnaires about risk preference. Cognition is a 27-point score composed of the word recall, serial sevens, and backward counting tests. 
Table A1-Categories of risk tolerance responses

\begin{tabular}{cccccc}
\hline \hline \multirow{2}{*}{$\begin{array}{c}\text { Response } \\
\text { category }\end{array}$} & $\begin{array}{c}\text { Downside risk of risky jobs } \\
\text { Accept }\end{array}$ & Reject & \multicolumn{2}{c}{ Bounds on Risk tolerance: $\theta$} & Fraction (\%) \\
\hline 1 & None & $1 / 10$ & 0 & Upper & \\
2 & $1 / 10$ & $1 / 5$ & 0.13 & 0.13 & 48.98 \\
3 & $1 / 5$ & $1 / 3$ & 0.27 & 0.50 & 17.36 \\
4 & $1 / 3$ & $1 / 2$ & 0.50 & 1.00 & 11.98 \\
5 & $1 / 2$ & $3 / 4$ & 1.00 & 3.27 & 9.54 \\
6 & $3 / 4$ & None & 3.27 & $\infty$ & 6.52 \\
\hline
\end{tabular}

Notes: The data come from the Health and Retirement Study (HRS) in 1994, 1998, 2000, 2002, and 2006 (N = 1,227). Respondents choose between a safe and a risky job in hypothetical scenarios. With equal chances, a risky job will double the income or cut monthly income by a specific fraction (downside risk). Varying the downside risk on the monthly income in subsequent questions refines the measure of risk preference. Panel (a) of Appendix Figure A1 shows the frequency distributions of risk choices. At the lower bound of the risk tolerance category $(\# 1)$, an individual rejects a risky job with the smallest downside risk. At the upper bound of the risk tolerance category (\#6), an individual accepts the largest downside risk. The exact wording of the questionnaire is presented in Appendix Table D1.

Table A2-Robustness checks: Risk tolerance (below thresholds)

\begin{tabular}{lccc}
\hline \hline & \multicolumn{3}{c}{ SS/income share } \\
\cline { 2 - 4 } & below 50 percent & below 40 percent & below 60 percent \\
& $(1)$ & $(2)$ & $(3)$ \\
\hline Week -2 & -0.025 & -0.073 & -0.029 \\
& $(0.096)$ & $(0.120)$ & $(0.083)$ \\
Week -1 & 0.068 & 0.045 & 0.146 \\
& $(0.109)$ & $(0.129)$ & $(0.100)$ \\
Week +2 & 0.103 & 0.089 & 0.123 \\
& $(0.087)$ & $(0.102)$ & $(0.079)$ \\
\hline Covariates & $\times$ & $\times$ & $\times$ \\
Mean of outcome & 0.559 & 0.576 & 0.560 \\
N & 700 & 546 & 846 \\
R squared & 0.185 & 0.191 & 0.142 \\
Sample share & 57 percent & 44 percent & 69 percent \\
\hline
\end{tabular}

Notes: The data come from the Health and Retirement Study (HRS) in 1994, 1998, 2000, 2002, and 2006. Column (1) replicates the baseline results of column (2) in Table 3. The sample is limited to SS/income share below $40 \%$ in columns (2), and below $60 \%$ in column (3). The outcome is risk tolerance. The estimates $\beta_{k}(k=-2,-1,+2)$ from equation [1] are reported with robust errors in parentheses. The omitted category is week +1 . Covariates include age, age squared, gender, household size, self-reported health indicators, highest years of schooling, marital status, race, retirement status, MSA status dummies, calendar week fixed effects (FEs), year FEs, month FEs, and year-month FEs. SS stands for Social Security. Significance levels: ${ }^{* * *} \mathrm{p}<0.01,{ }^{* *} \mathrm{p}<0.05,{ }^{*} \mathrm{p}<0.10$ 


\section{Table A3-Regression discontinuity analysis: Risk tolerance}

\begin{tabular}{lcc}
\hline \hline & $(1)$ & $(2)$ \\
\hline Before the pension payment & $\begin{array}{c}1.040^{* * *} \\
(0.192)\end{array}$ & $\begin{array}{c}1.243^{* * *} \\
(0.282)\end{array}$ \\
\hline Bandwidth (days) & 3.226 & 2.358 \\
Covariates & $\times$ & $\times$ \\
$\mathrm{N}$ & 527 & 527 \\
\hline
\end{tabular}

Notes: The data come from the Health and Retirement Study (HRS) in 1994, 1998, 2000, 2002, and 2006. The sample is limited to SS/income share above 50\%. SS stands for Social Security. The outcome is risk tolerance. Robust estimates are reported with robust standard errors in parentheses. One common mean square error optimal bandwidth selector for the RD treatment effect estimator is used in column (1), and one common coverage error rate optimal bandwidth selector for the RD treatment effect estimator is used in column (2). The regression is conducted using the "rdrobust" command in Stata software, developed by Calonico et al. (2014). Covariates include age, age squared, gender, total household income, self-reported health indicators, highest years of schooling, marital status, race, retirement status, MSA status dummies, and calendar week fixed effects. Significance levels: ${ }^{* * *} \mathrm{p}<0.01,{ }^{* *} \mathrm{p}<0.05,{ }^{*} \mathrm{p}<0.10$

\section{Table A4-Placebo: Risk tolerance}

\begin{tabular}{lcc}
\hline \hline & $\begin{array}{c}\text { People aged } \\
50 \text { to 61 years }\end{array}$ & $\begin{array}{c}\text { People aged 62+ } \\
\text { who do not receive SS }\end{array}$ \\
\hline Week -2 & $(1)$ & $(2)$ \\
Week -1 & 0.059 & -0.034 \\
& $(0.041)$ & $(0.114)$ \\
Week +2 & -0.008 & 0.081 \\
& $(0.041)$ & $(0.139)$ \\
Covariates & 0.057 & -0.141 \\
Mean of outcome & $(0.042)$ & $(0.120)$ \\
N & $\times$ & $\times$ \\
R squared & 0.588 & 0.479 \\
\hline
\end{tabular}

Notes: The data come from the Health and Retirement Study (HRS) in 1994, 1998, 2000, 2002, and 2006. The outcome is risk tolerance. The estimates $\beta_{k}(k=-2,-1,+2)$ from equation [1] are reported with robust errors in parentheses. The omitted category is week +1 . Covariates include age, age squared, gender, household size, self-reported health indicators, highest years of schooling, marital status, race, retirement status, MSA status dummies, calendar week fixed effects (FEs), year FEs, month FEs, and year-month FEs. Column (1) limits the sample to people aged 50-61 years who are younger than the eligibility age of 62 for Social Security. Column (2) limits the sample to people aged 62 and over who do not yet receive Social Security benefits. Significance levels: ${ }^{* * *} \mathrm{p}<0.01,{ }^{* *} \mathrm{p}<0.05,{ }^{*} \mathrm{p}<0.10$ 
Table A5-Robustness: Cognition

\begin{tabular}{|c|c|c|c|c|c|c|c|c|c|}
\hline & \multicolumn{3}{|c|}{$\begin{array}{l}\text { SS/income share } \\
\text { above } 50 \text { percent }\end{array}$} & \multicolumn{3}{|c|}{$\begin{array}{l}\text { SS/income share } \\
\text { above } 40 \text { percent }\end{array}$} & \multicolumn{3}{|c|}{$\begin{array}{l}\text { SS/income share } \\
\text { above } 60 \text { percent }\end{array}$} \\
\hline & $\begin{array}{c}\text { Normal } \\
(1)\end{array}$ & $\begin{array}{l}\text { CIND } \\
(2)\end{array}$ & $\begin{array}{c}\text { Dementia } \\
\text { (3) }\end{array}$ & $\begin{array}{c}\text { Normal } \\
(4)\end{array}$ & $\begin{array}{c}\text { CIND } \\
(5)\end{array}$ & $\begin{array}{c}\text { Dementia } \\
(6)\end{array}$ & $\begin{array}{c}\text { Normal } \\
(7)\end{array}$ & $\begin{array}{c}\text { CIND } \\
(8)\end{array}$ & $\begin{array}{c}\text { Dementia } \\
(9)\end{array}$ \\
\hline Week -2 & $\begin{array}{c}0.073 \\
(0.052)\end{array}$ & $\begin{array}{l}-0.062 \\
(0.053)\end{array}$ & $\begin{array}{l}-0.011 \\
(0.022)\end{array}$ & $\begin{array}{l}0.079^{*} \\
(0.044)\end{array}$ & $\begin{array}{l}-0.081^{*} \\
(0.044)\end{array}$ & $\begin{array}{c}0.001 \\
(0.019)\end{array}$ & $\begin{array}{c}0.044 \\
(0.066)\end{array}$ & $\begin{array}{l}-0.040 \\
(0.067)\end{array}$ & $\begin{array}{l}-0.003 \\
(0.027)\end{array}$ \\
\hline Week -1 & $\begin{array}{c}0.089 \\
(0.063)\end{array}$ & $\begin{array}{l}-0.065 \\
(0.063)\end{array}$ & $\begin{array}{l}-0.025 \\
(0.026)\end{array}$ & $\begin{array}{c}0.070 \\
(0.057)\end{array}$ & $\begin{array}{l}-0.049 \\
(0.057)\end{array}$ & $\begin{array}{l}-0.020 \\
(0.022)\end{array}$ & $\begin{array}{c}0.106 \\
(0.082)\end{array}$ & $\begin{array}{l}-0.085 \\
(0.080)\end{array}$ & $\begin{array}{l}-0.020 \\
(0.032)\end{array}$ \\
\hline Week +2 & $\begin{array}{c}0.071 \\
(0.051) \\
\end{array}$ & $\begin{array}{l}-0.037 \\
(0.052) \\
\end{array}$ & $\begin{array}{l}-0.034 \\
(0.024) \\
\end{array}$ & $\begin{array}{c}0.059 \\
(0.042) \\
\end{array}$ & $\begin{array}{l}-0.030 \\
(0.043) \\
\end{array}$ & $\begin{array}{l}-0.029 \\
(0.019) \\
\end{array}$ & $\begin{array}{c}0.049 \\
(0.064) \\
\end{array}$ & $\begin{array}{c}-0.019 \\
(0.065) \\
\end{array}$ & $\begin{array}{r}-0.030 \\
(0.030) \\
\end{array}$ \\
\hline Covariates & $\times$ & $\times$ & $\times$ & $\times$ & $\times$ & $\times$ & $\times$ & $\times$ & $\times$ \\
\hline Mean of outcome & 0.756 & 0.208 & 0.034 & 0.774 & 0.192 & 0.032 & 0.714 & 0.242 & 0.042 \\
\hline $\mathrm{N}$ & 518 & 518 & 518 & 670 & 670 & 670 & 375 & 375 & 375 \\
\hline R-squared & 0.278 & 0.207 & 0.308 & 0.247 & 0.178 & 0.284 & 0.381 & 0.238 & 0.347 \\
\hline
\end{tabular}

Notes: The data come from the Health and Retirement Study (HRS) in 1994, 1998, 2000, 2002, and 2006. Columns (1)-(3) replicate the baseline results of columns (1)-(3) in Table 6. The sample is limited to SS/income share above $40 \%$ in columns (4)-(6), and below $60 \%$ in columns (7)-(9). The classification is based on a 27-point score composed of the word recall, serial sevens, and backward counting tests. Scores between 12 and 27 are classified as normal, between 7 and 11 as cognitive impairment, not dementia (CIND), and between 0 and 6 as dementia. The estimates $\beta_{k}(k=-2,-1,+2)$ from equation [1] are reported with robust errors in parentheses. The omitted category is week +1 . Covariates include age, age squared, gender, household size, self-reported health indicators, highest years of schooling, marital status, race, retirement status, MSA status dummies, calendar week fixed effects (FEs), year FEs, month FEs, and year-month FEs. Significance levels: ${ }^{* * *} \mathrm{p}<0.01,{ }^{* *} \mathrm{p}<0.05,{ }^{*} \mathrm{p}<0.10$

Table A6-Robustness: Depression (below thresholds)

\begin{tabular}{lcccccc}
\hline & \multicolumn{7}{c}{ SS/income share } \\
\cline { 2 - 7 } & \multicolumn{2}{c}{ below 50 percent } & \multicolumn{2}{c}{ below 40 percent } & \multicolumn{2}{c}{ below 60 percent } \\
\hline & OLS & Probit & OLS & Probit & OLS & Probit \\
& $(1)$ & $(2)$ & $(3)$ & $(4)$ & $(5)$ & $(6)$ \\
\hline Week -2 & -0.030 & -0.003 & -0.044 & -0.039 & -0.028 & -0.023 \\
& $(0.041)$ & $(0.038)$ & $(0.038)$ & $(0.037)$ & $(0.033)$ & $(0.030)$ \\
Week -1 & -0.017 & -0.014 & -0.031 & -0.032 & -0.019 & -0.025 \\
& $(0.032)$ & $(0.032)$ & $(0.030)$ & $(0.028)$ & $(0.027)$ & $0.025)$ \\
Week +2 & -0.013 & -0.009 & $-0.065^{* *}$ & $-0.058^{* *}$ & $-0.062^{* *}$ & $-0.067^{* *}$ \\
& $(0.037)$ & $(0.032)$ & $(0.031)$ & $(0.029)$ & $(0.027)$ & $(0.028)$ \\
\hline Covariates & $\times$ & $\times$ & $\times$ & $\times$ & $\times$ & $\times$ \\
Mean of outcome & 0.078 & 0.094 & 0.085 & 0.096 & 0.087 & 0.096 \\
$\mathrm{~N}$ & 545 & 455 & 699 & 625 & 846 & 765 \\
Sample share & $44 \%$ & $37 \%$ & $57 \%$ & $51 \%$ & $69 \%$ & $62 \%$ \\
\hline
\end{tabular}

Notes: The data come from the Health and Retirement Study (HRS) in 1994, 1998, 2000, 2002, and 2006. The sample is limited to SS/income share above 50\% in columns (1) and (2), above 40\% in columns (3) and (4), and above 60\% in columns (5) and (6). The estimates $\beta_{k}(k=-2,-1,+2)$ from equation [1] are reported with robust errors in parentheses. The outcome is a dummy that takes the value of one if the person felt depressed much of the time during the past week. The omitted category is week +1 . Note that since the reference period of this question is a week from the survey date, we define the week dummies in equation [1] accordingly. Covariates include age, age squared, gender, household size, self-reported health indicators, highest years of schooling, marital status, race, retirement status, MSA status dummies, calendar week fixed effects (FEs), year FEs, month FEs, and year-month FEs. Significance levels: ${ }^{* * *} \mathrm{p}<0.01,{ }^{* *} \mathrm{p}<0.05,{ }^{*} \mathrm{p}<0.10$ 


\section{Appendix B: Analysis on risk preferences for Japan (JSTAR)}

\section{Figure B1-Frequency distributions: Risk preferences (JSTAR)}

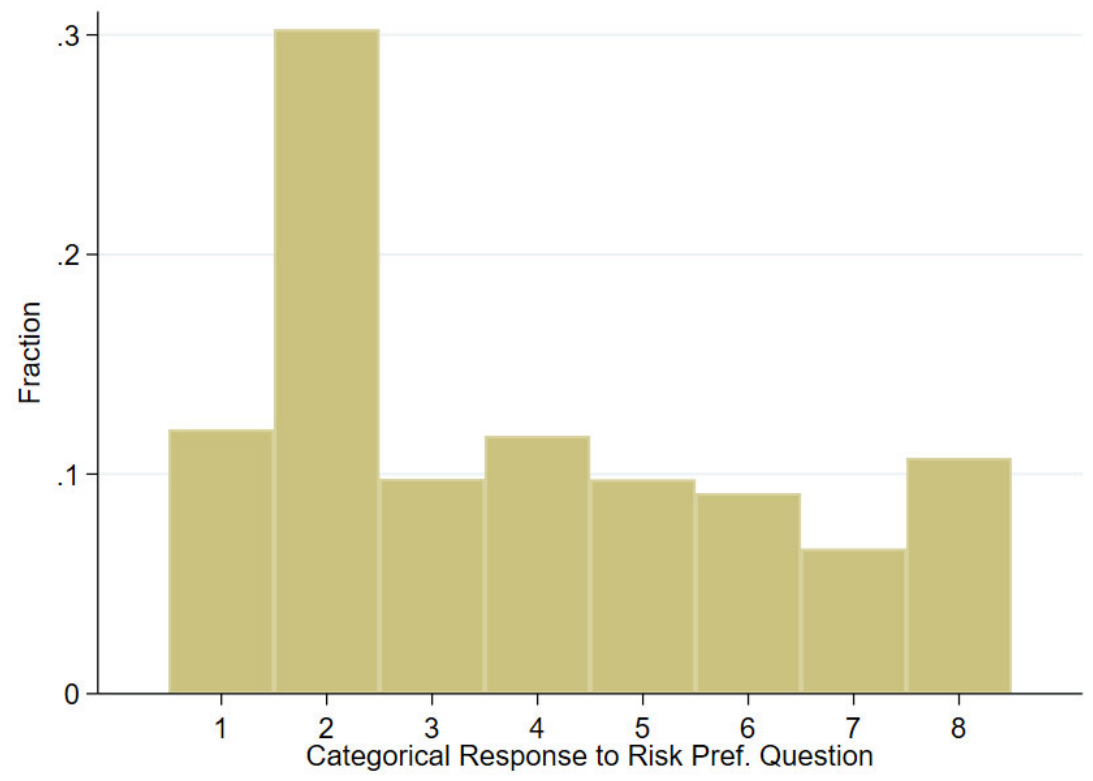

Notes: The data come from the Japanese Study of Aging and Retirement (JSTAR) in 2007, 2009, 2011, and 2013 (N = 2,728). Appendix Table B1 provides the relationship between the gamble response category and the downside risks that the individual accepts or rejects. The exact wording of the questionnaire is presented in Appendix Table D2 (N=2,705).

\section{Figure B2-Risk tolerance before and after payday (JSTAR)}

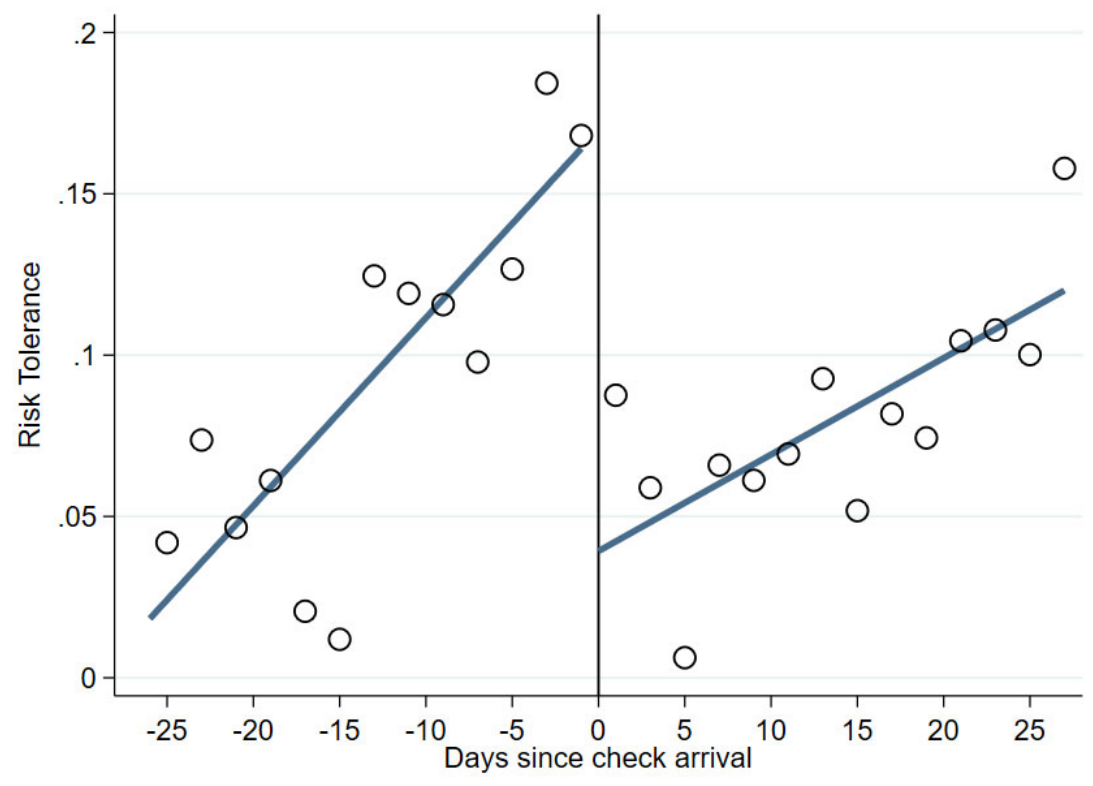

Notes: The data come from the Japanese Study of Aging and Retirement (JSTAR) in 2007, 2009, 2011, and 2013 (N=2728). Each plot represents the two-day average of risk tolerance residualized by survey-interview date fixed effects (FEs) four weeks before and after the check arrival. The survey-interview date FEs include dummy variables for the year, month, interactions of year and month, day of the week, number of weeks, and interactions of the day of week and number of the week. The line corresponds to the linear fit. See the main text for the construction of risk tolerance measures. Note that public pension benefit in Japan is paid on the $15^{\text {th }}$ of every other month. 
Table B1-Categories of risk tolerance responses (JSTAR)

\begin{tabular}{|c|c|c|c|c|c|}
\hline \multirow{2}{*}{$\begin{array}{l}\text { Response } \\
\text { category }\end{array}$} & \multicolumn{2}{|l|}{ Pay choices } & \multicolumn{2}{|c|}{ Bounds on Risk tolerance: $\theta$} & \multirow{2}{*}{$\begin{array}{l}\text { Fraction } \\
\quad(\%)\end{array}$} \\
\hline & Choice 1 & Choice 2 & Lower & Upper & \\
\hline 1 & $100 \%$ chance of an increase by $50 \%$ & & - & 0.00 & 12.02 \\
\hline 2 & $\begin{array}{l}90 \% \text { chance of an increase by } 50 \% \text { and } \\
10 \% \text { chance of an increase by } 5 \%\end{array}$ & & 0.00 & 0.06 & 30.24 \\
\hline 3 & $\begin{array}{l}80 \% \text { chance of an increase by } 50 \% \text { and } \\
20 \% \text { chance of an increase by } 5 \%\end{array}$ & & 0.06 & 0.08 & 9.79 \\
\hline 4 & $\begin{array}{l}70 \% \text { chance of an increase by } 50 \% \text { and } \\
30 \% \text { chance of an increase by } 5 \%\end{array}$ & $\begin{array}{l}100 \% \text { chance } \\
\text { of an increase }\end{array}$ & 0.08 & 0.11 & 11.73 \\
\hline 5 & $\begin{array}{l}60 \% \text { chance of an increase by } 50 \% \text { and } \\
40 \% \text { chance of an increase by } 5 \%\end{array}$ & by $20 \%$ & 0.11 & 0.16 & 9.75 \\
\hline 6 & $\begin{array}{l}50 \% \text { chance of an increase by } 50 \% \text { and } \\
50 \% \text { chance of an increase by } 5 \%\end{array}$ & & 0.16 & 0.25 & 9.13 \\
\hline 7 & $\begin{array}{l}40 \% \text { chance of an increase by } 50 \% \text { and } \\
60 \% \text { chance of an increase by } 5 \%\end{array}$ & & 0.25 & 0.62 & 6.6 \\
\hline 8 & - & & 0.62 & $\infty$ & 10.74 \\
\hline
\end{tabular}

Notes: The data come from the Japanese Study of Aging and Retirement (JSTAR) in 2007, 2009, 2011, and $2013(\mathrm{~N}=2,728)$. Respondents choose income from two scenarios where the safe option guarantees a $20 \%$ increase in income, while the risky option increases the income by either $50 \%$ or $5 \%$ with a specific probability. Varying the downside risk on risky options refines the measure of risk preference. At the upper bound of the risk tolerance category (\#8), an individual accepts the largest downside risk. Appendix Figure B1 shows the frequency distributions of risk choices. The exact wording of the questionnaire is presented in Appendix Table D2. 
Table B2-Descriptive statistics (JSTAR)

\begin{tabular}{|c|c|c|c|c|c|}
\hline Variables & Obs & Mean & SD & Min & Max \\
\hline Risk tolerance: $\theta$ & 2728 & 0.153 & 0.195 & 0 & 0.622 \\
\hline Days since check arrival & 2728 & -0.932 & 15.094 & -28 & 27 \\
\hline Social Security Benefits / Household Income & 2388 & 0.642 & 0.313 & 0 & 1 \\
\hline \multicolumn{6}{|l|}{ Individual Characteristics: } \\
\hline Age & 2728 & 68.515 & 4.992 & 51 & 81 \\
\hline Female & 2728 & 0.510 & 0.500 & 0 & 1 \\
\hline \multicolumn{6}{|l|}{ Education } \\
\hline Elementary/Middle school & 2728 & 0.310 & 0.463 & 0 & 1 \\
\hline High School & 2728 & 0.458 & 0.498 & 0 & 1 \\
\hline Junior College & 2728 & 0.039 & 0.194 & 0 & 1 \\
\hline Vocational School & 2728 & 0.059 & 0.235 & 0 & 1 \\
\hline University or above & 2728 & 0.126 & 0.332 & 0 & 1 \\
\hline Married & 2728 & 0.803 & 0.398 & 0 & 1 \\
\hline Not working & 2728 & 0.615 & 0.487 & 0 & 1 \\
\hline Good Health & 2728 & 0.342 & 0.475 & 0 & 1 \\
\hline Poor Health & 2728 & 0.138 & 0.345 & 0 & 1 \\
\hline
\end{tabular}

Notes: The data come from the Japanese Study of Aging and Retirement (JSTAR) in 2007, 2009, 2011, and 2013.

Table B3-Test for randomization of interview dates (JSTAR)

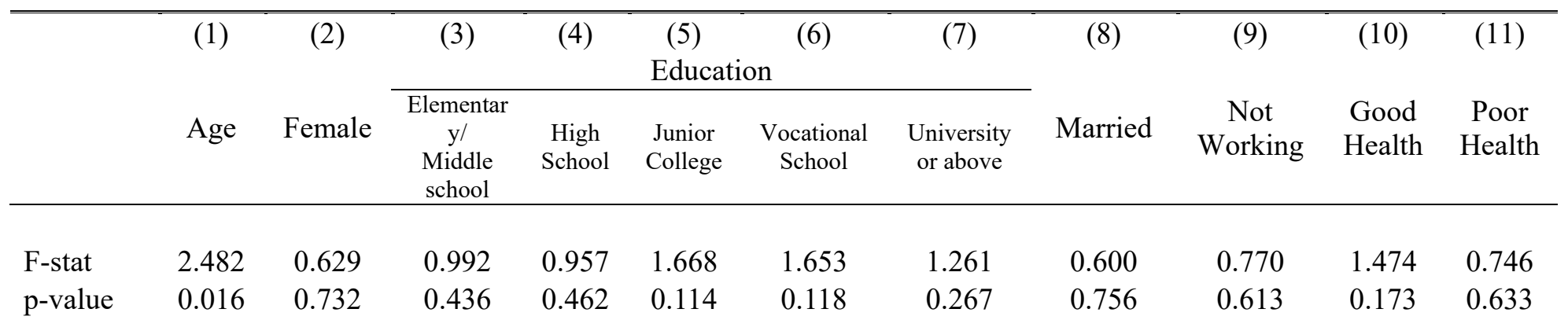

Notes: The data come from the Japanese Study of Aging and Retirement (JSTAR) in 2007, 2009, 2011, and 2013 (N = 2,728). F-stats and p-values correspond to joint null tests whereby each coefficient on the eight-week dummies is zero. 
Table B4-Robustness checks: Risk tolerance (JSTAR)

\begin{tabular}{|c|c|c|c|}
\hline & $\begin{array}{c}\text { Risk tolerance } \\
\text { categories } \\
7 \text { or } 8 \\
(1)\end{array}$ & $\begin{array}{c}\text { Ordered } \\
\text { Probit } \\
(2)\end{array}$ & $\begin{array}{c}\text { Interval } \\
\text { regression } \\
\text { (3) }\end{array}$ \\
\hline Week -4 & $\begin{array}{l}-0.057 \\
(0.062)\end{array}$ & $\begin{array}{c}0.048 \\
(0.173)\end{array}$ & $\begin{array}{c}-0.022 \\
(0.034)\end{array}$ \\
\hline Week -3 & $\begin{array}{c}-0.070 \\
(0.076)\end{array}$ & $\begin{array}{l}-0.023 \\
(0.208)\end{array}$ & $\begin{array}{l}-0.032 \\
(0.042)\end{array}$ \\
\hline Week -2 & $\begin{array}{c}0.047 \\
(0.059)\end{array}$ & $\begin{array}{c}-0.012 \\
(0.167)\end{array}$ & $\begin{array}{c}0.036 \\
(0.033)\end{array}$ \\
\hline Week -1 & $\begin{array}{c}0.102 * \\
(0.054)\end{array}$ & $\begin{array}{c}0.118 \\
(0.153)\end{array}$ & $\begin{array}{c}0.064 * * \\
(0.030)\end{array}$ \\
\hline Week +2 & $\begin{array}{c}0.015 \\
(0.048)\end{array}$ & $\begin{array}{c}0.068 \\
(0.122)\end{array}$ & $\begin{array}{c}0.006 \\
(0.027)\end{array}$ \\
\hline Week +3 & $\begin{array}{c}-0.036 \\
(0.057)\end{array}$ & $\begin{array}{c}-0.037 \\
(0.159)\end{array}$ & $\begin{array}{c}-0.002 \\
(0.032)\end{array}$ \\
\hline Week +4 & $\begin{array}{c}0.030 \\
(0.065)\end{array}$ & $\begin{array}{c}0.043 \\
(0.181)\end{array}$ & $\begin{array}{c}0.031 \\
(0.037)\end{array}$ \\
\hline Covariates & $x$ & $x$ & $x$ \\
\hline Mean of outcome & 0.173 & 3.844 & - \\
\hline $\mathrm{N}$ & 2728 & 2728 & 2728 \\
\hline
\end{tabular}

Notes: The data come from the Japanese Study of Aging and Retirement (JSTAR) in 2007, 2009, 2011, and 2013. The outcome is risk tolerance. The outcome in column (1) is a binary measure of risk preference that takes the value of 1 if the person chose the highest or second-highest risk tolerance categories (categories 7 or 8 ) and 0 otherwise. The outcome in column (2) is an ordinal measure of risk preference coded from 1 for the lowest risk tolerance category to 8 for the highest category. Column (3) reports the results of interval regression. The estimates $\beta_{k}(k=-4,-3,-2,-1,+2,+3,+4)$ from equation [1]' are reported with robust errors in parentheses. The omitted category is week +1 . Covariates include age, age squared, and dummy variables for gender, marital status, educational background, sampling cohort, working status, and good and bad health status. Time effects are related to the date of the survey interview and include dummy variables for the year, month, interactions of year and month, day of the week, number of weeks, and interactions of the day of week and number of weeks of the interview date. See the main text for the construction of risk preference measures. Significance levels: ${ }^{* * *} \mathrm{p}<0.01,{ }^{* *} \mathrm{p}<0.05,{ }^{*} \mathrm{p}<0.10$ 


\section{Table B5-Placebo: Risk tolerance (JSTAR)}

\begin{tabular}{|c|c|c|}
\hline & $\begin{array}{l}\text { People aged } \\
50 \text { to } 59 \text { years } \\
\text { (1) }\end{array}$ & $\begin{array}{c}\text { People aged } 60+ \\
\text { who do not receive pension } \\
\text { (2) }\end{array}$ \\
\hline Week -4 & $\begin{array}{c}0.047 \\
(0.057)\end{array}$ & $\begin{array}{l}-0.022 \\
(0.087)\end{array}$ \\
\hline Week -3 & $\begin{array}{l}-0.035 \\
(0.077)\end{array}$ & $\begin{array}{c}0.014 \\
(0.115)\end{array}$ \\
\hline Week -2 & $\begin{array}{c}0.032 \\
(0.064)\end{array}$ & $\begin{array}{l}-0.060 \\
(0.095)\end{array}$ \\
\hline Week -1 & $\begin{array}{c}-0.004 \\
(0.064)\end{array}$ & $\begin{array}{c}-0.038 \\
(0.100)\end{array}$ \\
\hline Week +2 & $\begin{array}{l}-0.050 \\
(0.044)\end{array}$ & $\begin{array}{c}0.056 \\
(0.062)\end{array}$ \\
\hline Week +3 & $\begin{array}{c}0.013 \\
(0.060)\end{array}$ & $\begin{array}{l}-0.039 \\
(0.078)\end{array}$ \\
\hline Week +4 & $\begin{array}{c}0.080 \\
(0.066)\end{array}$ & $\begin{array}{l}-0.079 \\
(0.097)\end{array}$ \\
\hline Covariates & $x$ & $x$ \\
\hline Mean of outcome & 0.176 & 0.151 \\
\hline $\mathrm{N}$ & 765 & 336 \\
\hline
\end{tabular}

Notes: The data come from the Japanese Study of Aging and Retirement (JSTAR) in 2007, 2009, 2011, and 2013. The outcome is risk tolerance. The estimates $\beta_{k}(k=-4,-3,-2,-1,+2,+3,+4)$ from equation [1]' are reported with robust errors in parentheses. The omitted category is week +1 . Covariates include age, age squared, and dummy variables for gender, marital status, educational background, sampling cohort, working status, and good and bad health status. Time effects are related to the date of the survey interview and include dummy variables for the year, month, interactions of year and month, day of the week, number of weeks, and interactions of the day of week and number of weeks of the interview date. See the main text for the construction of risk preference measures. Column (1) limits the sample to people aged 50-59 years who are younger than the eligibility age of 60 for pension. Column (2) limits the sample to people aged 60 and over who do not yet receive pension benefits. Significance levels: ${ }^{* * *} \mathrm{p}<0.01,{ }^{* *} \mathrm{p}<0.05,{ }^{*} \mathrm{p}<0.10$ 


\section{Appendix C: Analysis for Japan (JGSS)}

\section{Figure C1-Frequency distributions (JGSS)}

(a) Financial anxiety $(\mathrm{N}=277)$

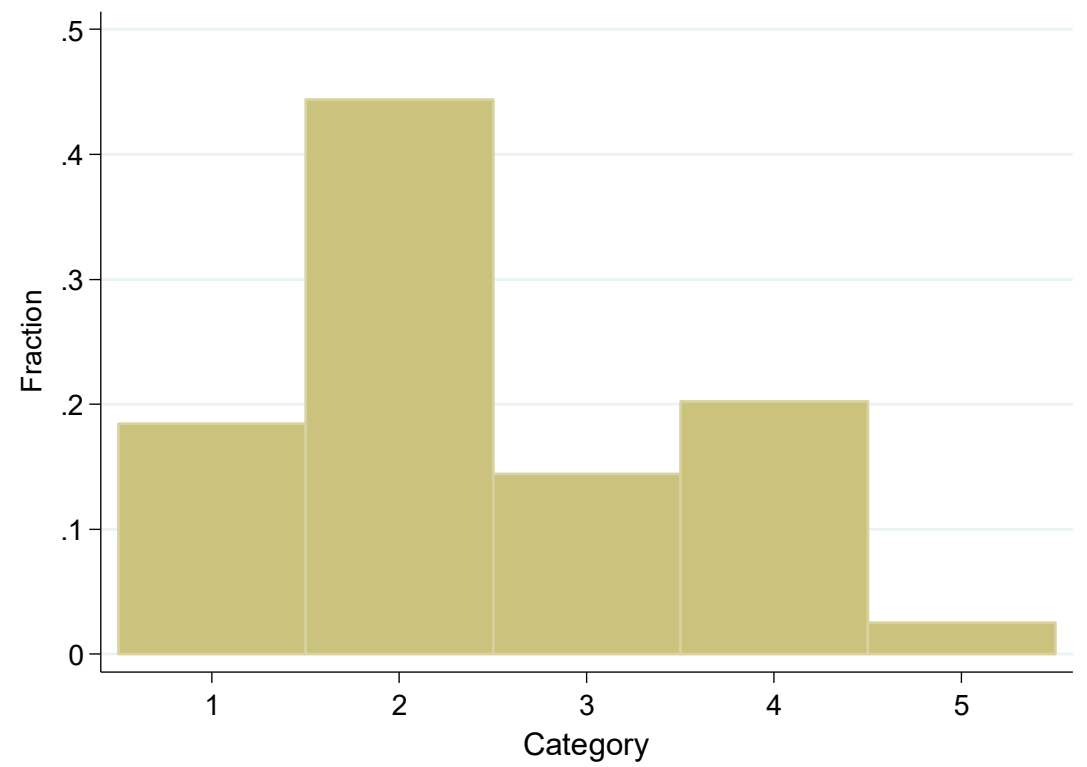

(b) Self-perceived social status $(\mathrm{N}=593)$

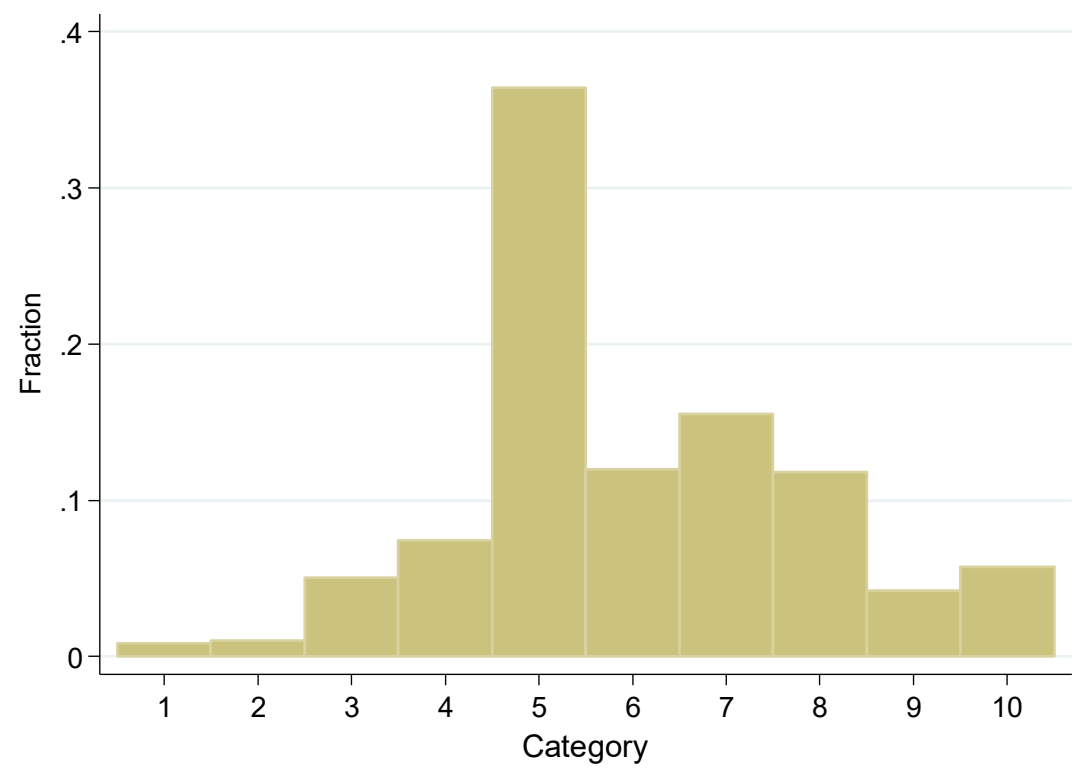

Notes: The data come from the Japanese General Social Surveys (JGSS) in 2008. The question on financial anxiety is "Do you feel anxious about your economic situation in the future?" The categories 1 to 5 correspond to "I feel very anxious", "I feel somewhat anxious", "I have mixed feelings", "I don’t feel anxious very much", and "I don't feel anxious at all." The question on self-perceived social status is "If we were to divide the contemporary Japanese society into the following ten strata, which would you say you belong to?" and categories range from 1 (top) to 10 (bottom). 


\section{Figure C2-Outcomes before and after payday (JGSS)}

(a) Feel financialy anxious $(\mathrm{N}=277)$

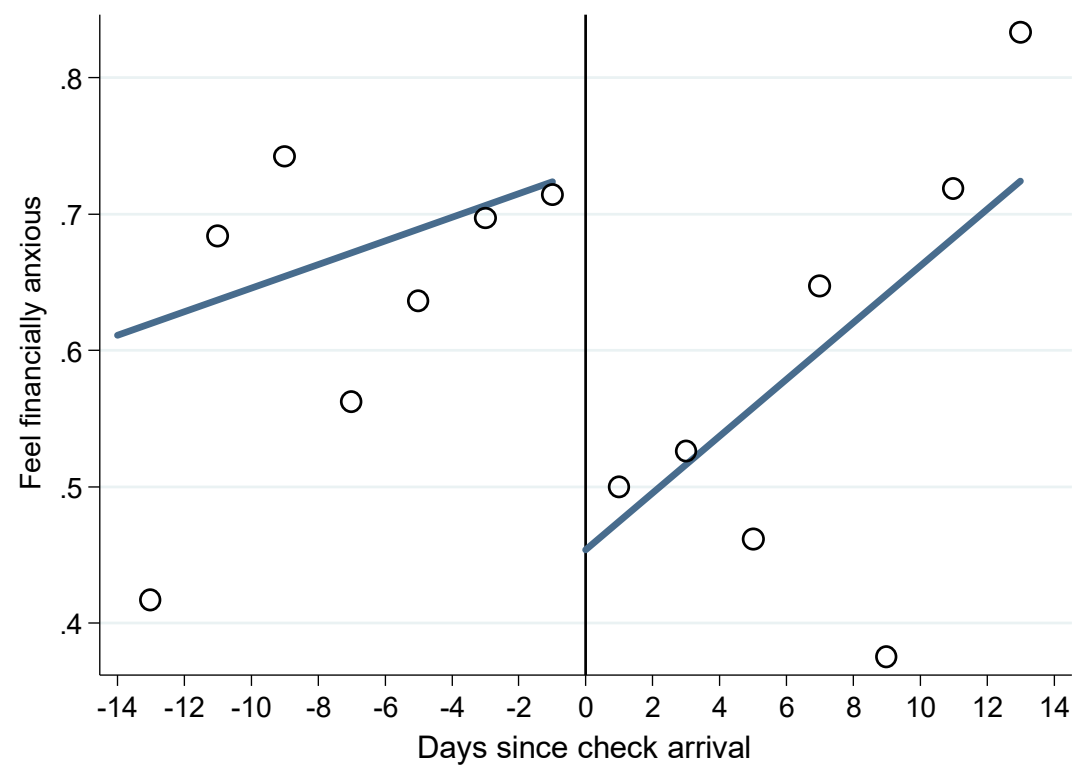

(b) Low self-perceived social status $(\mathrm{N}=593)$

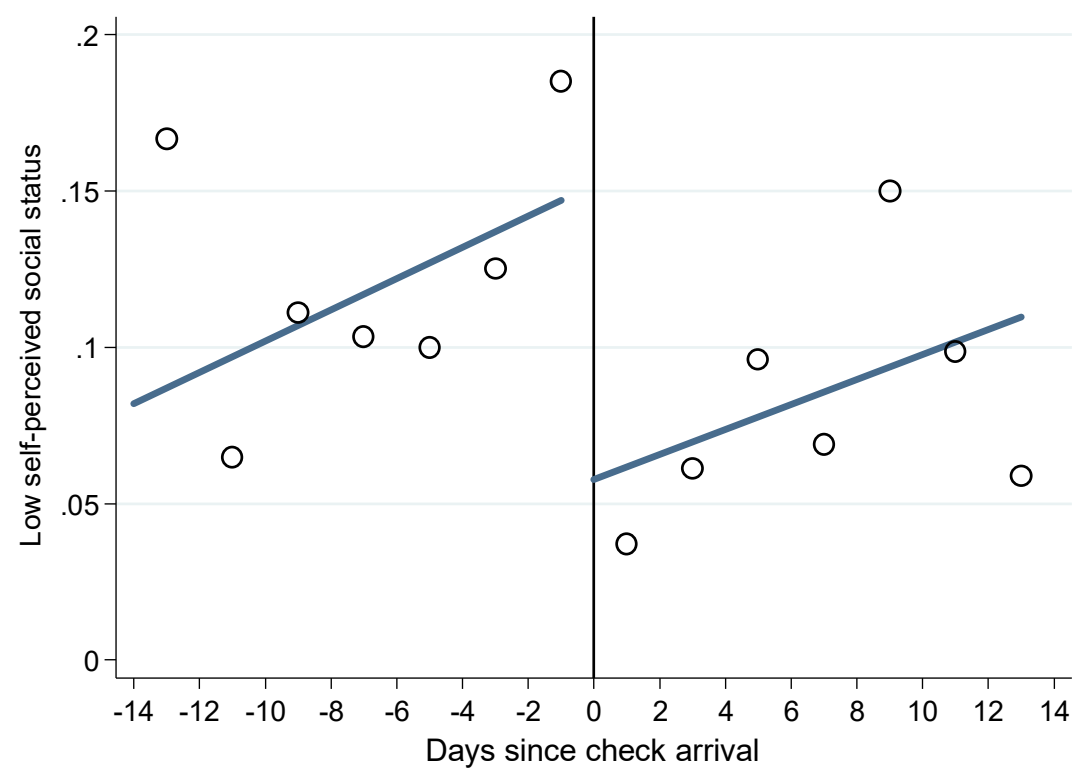

Notes: The data come from the Japanese General Social Surveys (JGSS) in 2008. Each plot represents the two-day average of outcomes for two weeks before and after payday. The line corresponds to the linear fit. The outcome in panel (a) is a dummy that takes the value of one if the respondents choose either "I feel very anxious" or "I feel somewhat anxious" to the question "Do you feel anxious about your economic situation in the future?" or zero otherwise. The outcome in panel (b) is a dummy that takes the value of one if the respondents choose the lowest and second-lowest categories (categories 9 and 10) to the question "If we were to divide the contemporary Japanese society into the following ten strata, which would you say you belong to?" or zero otherwise. 
Table C1-Descriptive statistics (JGSS)

\begin{tabular}{lrrrrr}
\hline \hline Variables & \multicolumn{1}{c}{ Obs } & \multicolumn{1}{c}{ Mean } & SD & Min & Max \\
\hline Feel financially anxious & & & & & \\
Low self-perceived social status & 277 & 0.628 & 0.484 & 0 & 1 \\
Days since check arrival & 593 & 0.099 & 0.3 & 0 & 1 \\
Individual Characteristics: & 593 & -1.501 & 7.985 & -14 & 13 \\
Age & & & & & \\
Female & 593 & 71.321 & 6.678 & 60 & 89 \\
Education & 593 & 0.501 & 0.5 & 0 & 1 \\
$\quad$ & & & & & \\
$\quad$ Elementary/Middle school & 593 & 0.456 & 0.498 & 0 & 1 \\
$\quad$ Jigh School & 593 & 0.341 & 0.474 & 0 & 1 \\
$\quad 59 n i o r$ College & 593 & 0.015 & 0.122 & 0 & 1 \\
$\quad$ Vocational School & 593 & 0.053 & 0.225 & 0 & 1 \\
$\quad$ University or above & 593 & 0.126 & 0.333 & 0 & 1 \\
Married & 593 & 0.752 & 0.432 & 0 & 1 \\
Not working & 593 & 0.839 & 0.368 & 0 & 1 \\
Good Health & 593 & 0.459 & 0.499 & 0 & 1 \\
Poor Health & 593 & 0.211 & 0.409 & 0 & 1 \\
\hline
\end{tabular}

Notes: The data come from the JGSS in 2008. "Feel financially anxious" is a dummy that takes the value of one if the respondents choose either "I feel very anxious" or "I feel somewhat anxious" to the question "Do you feel anxious about your economic situation in the future?" or zero otherwise. "Low position in the society" is a dummy that takes the value of one if the respondents choose the lowest and second lowest categories (categories 9 and 10) to the question "If we were to divide the contemporary Japanese society into the following ten strata, which would you say you belong to?" or zero otherwise. "Feel financially anxious" is asked to only half of the respondents.

Table C2-Test for randomization of interview dates (JGSS)

\begin{tabular}{|c|c|c|c|c|c|c|c|c|c|c|c|}
\hline \multirow[t]{3}{*}{ 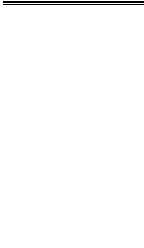 } & (1) & (2) & (3) & (4) & (5) & (6) & (7) & (8) & (9) & (10) & (11) \\
\hline & \multicolumn{11}{|c|}{ Education } \\
\hline & Age & Female & $\begin{array}{c}\text { Elementary/ } \\
\text { Middle } \\
\text { school }\end{array}$ & $\begin{array}{l}\text { High } \\
\text { School }\end{array}$ & $\begin{array}{l}\text { Junior } \\
\text { College }\end{array}$ & $\begin{array}{c}\text { Vocational } \\
\text { School }\end{array}$ & $\begin{array}{c}\text { University } \\
\text { or above }\end{array}$ & Married & $\begin{array}{c}\text { Not } \\
\text { Working }\end{array}$ & $\begin{array}{l}\text { Good } \\
\text { Health }\end{array}$ & $\begin{array}{l}\text { Poor } \\
\text { Health }\end{array}$ \\
\hline F-stat & 0.596 & 0.157 & 0.800 & 1.144 & 0.295 & 0.949 & 0.826 & 1.701 & 2.922 & 0.740 & 2.096 \\
\hline $\mathrm{p}$-value & 0.618 & 0.925 & 0.494 & 0.330 & 0.829 & 0.416 & 0.480 & 0.166 & 0.033 & 0.529 & 0.100 \\
\hline
\end{tabular}

Notes: The data come from the JGSS in $2008(\mathrm{~N}=593)$. F-stats and p-values correspond to joint null tests whereby each of the coefficients on the four-week dummies is zero. 


\section{Table C3-Robustness checks: Potential mechanisms (JGSS)}

\begin{tabular}{|c|c|c|}
\hline \multirow[t]{2}{*}{ Outcome: } & $\begin{array}{c}\text { Feel financially } \\
\text { anxious }\end{array}$ & $\begin{array}{l}\text { Low self-perceived } \\
\text { social status }\end{array}$ \\
\hline & $\begin{array}{c}\text { Ordered } \\
\text { Probit } \\
\text { (1) }\end{array}$ & $\begin{array}{c}\text { Ordered } \\
\text { Probit } \\
\text { (2) }\end{array}$ \\
\hline Week -2 & $\begin{array}{c}0.521 * * \\
(0.227)\end{array}$ & $\begin{array}{c}0.005 \\
(0.132)\end{array}$ \\
\hline Week -1 & $\begin{array}{c}0.659 * * * \\
(0.228)\end{array}$ & $\begin{array}{l}0.216^{*} \\
(0.130)\end{array}$ \\
\hline Week +2 & $\begin{array}{c}0.318 \\
(0.259)\end{array}$ & $\begin{array}{c}0.134 \\
(0.136)\end{array}$ \\
\hline Covariates & $x$ & $x$ \\
\hline Mean of outcome & 3.560 & 6.000 \\
\hline $\mathrm{N}$ & 277 & 593 \\
\hline
\end{tabular}

Notes: The data come from the Japanese General Social Surveys (JGSS) in 2008. The estimates $\beta_{k}(k=-2,-1,+2)$ from estimating an equation [1] are reported with robust errors in parentheses. The omitted category is week +1 . The outcome in column (1) is an ordinal measure of financial anxiety coded from 1 for "I don't feel anxious at all" to 5 for "I feel very anxious" to the question "Do you feel anxious about your economic situation in the future?". The outcome in column (2) is an ordinal measure of position in the society coded from 1 for "top" to 10 for "bottom" to the question "If we were to divide the contemporary Japanese society into the following ten strata, which would you say you belong to?" Covariates include dummy variables for age, gender, marital status, educational background, working status, good and bad health status, region fixed effects (FEs), and month FEs. Significance levels: ${ }^{* * *} \mathrm{p}<0.01,{ }^{* *} \mathrm{p}<0.05,{ }^{*}$ $\mathrm{p}<0.10$

Table C4-Placebo: Potential mechanisms (JGSS)

\begin{tabular}{lccccc}
\hline \hline Outcome: & \multicolumn{2}{c}{ Feel financially anxious } & & \multicolumn{2}{c}{ Low self-perceived social status } \\
\cline { 2 - 3 } \cline { 5 - 6 } & OLS & Probit & & OLS & Probit \\
& $(1)$ & $(2)$ & & $(3)$ & $(4)$ \\
\hline Week -2 & 0.122 & 0.101 & & 0.024 & 0.028 \\
& $(0.091)$ & $(0.082)$ & & $(0.044)$ & $(0.040)$ \\
Week -1 & -0.043 & -0.030 & & -0.000 & 0.009 \\
& $(0.103)$ & $(0.071)$ & & $(0.039)$ & $(0.038)$ \\
Week +2 & 0.084 & 0.088 & & -0.033 & -0.051 \\
& $(0.088)$ & $(0.070)$ & & $(0.028)$ & $(0.036)$ \\
\hline Covariates & $\times$ & $\times$ & & $\times$ & $\times$ \\
Mean of outcome & 0.787 & 0.789 & & 0.068 & 0.081 \\
N & 221 & 218 & & 428 & 358 \\
R squared & 0.216 & - & & 0.118 & - \\
\hline
\end{tabular}

Notes: The data come from the Japanese General Social Surveys (JGSS) in 2008. The sample is limited to people aged 50-59 years who do not receive a pension benefit. The estimates $\beta_{k}(k=-2,-1,+2)$ from estimating an equation [1] are reported with robust errors in parentheses. The omitted category is week +1 . The outcome in column (1) is a dummy that takes the value of one if the respondents choose either "I feel very anxious" or "I feel somewhat anxious" to the question "Do you feel anxious about your economic situation in the future?" or zero otherwise. The outcome in column (2) is a dummy that takes the value of one if the respondents choose the lowest and second-lowest categories (categories 9 and 10) to the question "If we were to divide the contemporary Japanese society into the following ten strata, which would you say you belong to?" or zero otherwise. Covariates include dummy variables for age, gender, marital status, educational background, working status, good and bad health status, region fixed effects (FEs), and month FEs. Significance levels: ${ }^{* * *} \mathrm{p}<0.01,{ }^{* *} \mathrm{p}<0.05,{ }^{*} \mathrm{p}<0.10$ 


\section{Appendix D: Data Appendix}

\section{Table D1-Questionnaire for the HRS}

Question 0:

Suppose that you are the only income earner in the family. Your doctor recommends that you move because of allergies, and you have to choose between two possible jobs.

The first would guarantee your current total family income for life. The second is possibly better paying, but the income is also less certain. There is a 50-50 chance the second job would double your total lifetime income and a 50-50 chance that it would cut it by a third. Which job would you take -- the first job or the second job?

1. FIRST JOB $\rightarrow$ to Question C

2. SECOND JOB $\rightarrow$ to Question A

8. Don't know / Not available $\rightarrow$ End

9. Refuse $\rightarrow$ End

Question A:

Suppose the chances were 50-50 that the second job would double your lifetime income, and 50-50 that it would cut it in half. Would you take the first job or the second job?

1. FIRST JOB $\rightarrow$ End

2. SECOND JOB $\rightarrow$ to Question B

8. Don't know / Not available $\rightarrow$ End

9. Refuse $\rightarrow$ End

Question B:

Suppose the chances were 50-50 that the second job would double your lifetime income and 50-50 that it would cut it by seventy-five percent. Would you take the first job or the second job?

1. FIRST JOB $\rightarrow$ End

2. SECOND JOB $\rightarrow$ End

8. Don't know / Not available $\rightarrow$ End

9. Refuse $\rightarrow$ End

Question C:

Suppose the chances were 50-50 that the second job would double your lifetime income and 50-50 that it would cut it by twenty percent. Would you take the first job or the second job?

1. FIRST JOB $\rightarrow$ to Question D

2. SECOND JOB $\rightarrow$ End

8. Don't know / Not available $\rightarrow$ End

9. Refuse $\rightarrow$ End

Question D:

Suppose the chances were 50-50 that the second job would double your lifetime income and 50-50 that it would cut it by 10 percent. Would you take the first job or the second job?

1. FIRST JOB $\rightarrow$ End

2. SECOND JOB $\rightarrow$ End

8. Don't know / Not available $\rightarrow$ End

9. Refuse $\rightarrow$ End 


\section{Table D2 - Questionnaire for JSTAR}

Question: Suppose how you are paid at work were to change next month only, which of the following options would you prefer? Please assume that the amount of your pay is not related to your ability or effort and that this change will be in effect for the next month only.

Choice 1

Choice 2

$100 \%$ chance of an increase by $50 \%$

$90 \%$ chance of an increase by $50 \%$ and

$10 \%$ chance of an increase by $5 \%$

$80 \%$ chance of an increase by $50 \%$ and

$20 \%$ chance of an increase by $5 \%$

$70 \%$ chance of an increase by $50 \%$ and

$30 \%$ chance of an increase by $5 \%$

$100 \%$ chance of an increase by $20 \%$

$60 \%$ chance of an increase by $50 \%$ and

$40 \%$ chance of an increase by $5 \%$

$50 \%$ chance of an increase by $50 \%$ and

$50 \%$ chance of an increase by $5 \%$

$40 \%$ chance of an increase by $50 \%$ and

$60 \%$ chance of an increase by $5 \%$ 